\title{
ASSET MARKET REACTIONS TO NEWS: AN EXPERIMENTAL STUDY
}

by

\author{
Gunduz Caginalp ${ }^{\mathrm{a}}$, Li Hao ${ }^{\mathrm{b}}$, David Porter ${ }^{\mathrm{c}}$ and Vernon $\mathrm{Smith}^{\mathrm{c}}$
}

${ }^{a}$ Department of Mathematics, University of Pittsburgh, Pittsburgh, PA, USA 15260,

Phone 412-624-8375, Fax: 412-624-839, e-mail: caginalp@pitt.edu

${ }^{b}$ Interdisciplinary Center for Economic Science, George Mason University, Fairfax, VA 22030

Phone: 703-993-4850 Fax: 714-993-4851E-mail:lhao@gmu.edu

${ }^{c}$ Economic Science Institute, Chapman University, Orange, CA 92866

Phone: 714-628-2830 Fax: 714-532-6081 E-mail:dporter@chapman E-mail: vsmith@chapman.edu 


\title{
ASSET MARKET REACTIONS TO NEWS: \\ AN EXPERIMENTAL STUDY
}

\begin{abstract}
An experimental asset market is used to test the effect of news concerning the underlying value of an asset on its trading price. Statistical support is found for the hypothesis that investors underreact to news on asset valuation. The results are consistent with the viewpoint that price and valuation history have a significant effect on trader behavior. Two sets of experiments involve a single asset with a single payout at the end of the experiment. Payout conditions are updated at the midpoint of the market trading period. The two sets of experiments have different payout expectations during the first half of the experiment but the payout expectations are identical after the midpoint._Although the expected payouts are identical after the midpoint of the market trading periods, the trading prices for the two sets of experiments differ significantly even after their payout expectations coincide. This provides support for underreaction and indicates that decision makers tend to "anchor" their price expectations to pre-existing prices and/or valuations.
\end{abstract}




\section{Introduction}

In classical finance, one has the basic hypothesis that public information is available to everyone. While it is acknowledged that not everyone will find or appreciate this information, there is the assumption of a huge amount of capital that can utilize this knowledge to exploit any market inefficiency, thereby restoring the asset price to its true value. Hence, efficient market theorists would argue that the market price of a security can be determined, for all practical purposes, by the assumption that everyone is perfectly informed. Furthermore, although not everyone will agree on the correct value of a security, the market acts as though there were unanimity among market participants on this assessment. Thus, the classical theory would stipulate that the perturbations in asset prices have two sources: one is due to the randomness of the news entering the market, the other is a small amount of randomness due to mistakes made by some investors that are quickly exploited by the better informed.

Although the viewpoint expressed above is espoused by many academic theorists and practitioners offering index funds, it is sharply challenged by market practitioners, particularly those who are involved in managed funds. These practitioners --who typically charge one or two percent of the fund's value per year for selecting assets to hold in their portfolio and timing their purchases and sales-- believe that there are a number of factors that distort prices, enabling a skilled manager the opportunity to buy at bargain prices and sell at full value or higher. In fact, hedge fund managers typically charge these fees plus about $30 \%$ of the yearly profits. Hence, the debate of market efficiency is more than academic.

This assertion that asset markets are efficient because they instantaneously incorporate all public information into a unique assessment of value via asset prices has been questioned from a number of perspectives. Studies of market data have often concluded that market volatility is excessive when measured against classical concepts of valuation (Shiller 1981 and Pontiff 1997; see for example). 
The possibility that large numbers of investors may have systematic biases has attracted the attention of the academic finance and economics communities in recent years and has led to the rapidly growing area known as behavioral finance. Among these biases is the concept of "anchoring" whereby a decision maker focuses on a particular value or set of values for the asset, and neglects the possibility that the true value is very different from these (Shefrin 2005). Another is the concept of "affect" whereby an attractive and appealing idea mesmerizes the investor so that a realistic assessment of value is short-circuited (Slovic et al. 2002). Analogously, a company that is involved in a business that is unpleasant or unexciting will often be out of favor. Oil companies are often considered to be within this "ugly duckling" group until energy prices soar. Often a stock or industry that is out of favor tends to remain at suppressed prices (i.e., a trading price that is low by measures of price/earnings, price/book ratios, etc.) reinforcing the undesirability. There is also the possibility that a stock with a suppressed price is also a victim of anchoring, i.e., investors have become accustomed to observing the low stock price, and are skeptical of any improvement in price, and thereby fail to react optimally when there is evidence that the situation has turned around. Hence, this could be a fundamental origin of underreaction, and could be tested experimentally. Alternatively, if the market price were to increase disproportionately to news of improving prospects, it would suffer from an overreaction to news. Both under- and over- reaction have been noted in the behavioral finance literature. Without clear criteria for the situations in which one can expect underreaction rather than the overreaction, it becomes easy for efficient market theorists to claim that if one cannot distinguish a priori between the two, the market must be efficient.

One of the underlying causes for over-reaction may be explained through the "representativeness heuristic" (Grether 1980). In an early paper on behavioral influences, Grether designed a two-stage experiment in which participants were asked to make a choice in which the "ticket" payout depended on whether the regime was "strong" or "weak." A signal was received at the second stage that increased slightly the probability that the regime was strong. Using a Bayesian probability formulation to recalculate the posterior odds, it would be clear that the probabilities are only slightly changed, and the 
value of the ticket would be slightly higher. However, since the new signal is representative of a strong process, a participant who is subject to this behavioral bias will tend to overvalue the ticket. Thus, one can view representativeness as a key cause of overreaction. There may be many other reasons for overreaction in the markets. For example, in a competitive situation (e.g., a money manager who must keep up with the index average performance) one might recognize that some news is not terribly significant in the long run, but may fear that the others will not share this calculation. Hence, there is an incentive to increase one's positions in an asset based upon the uncertainty involving others' reactions. As noted in Smith, Suchanek and Williams (1998), even when there is no uncertainty about the ultimate payout, there is the uncertainty involving others' actions. In the fundamental experiments of Beard and Beil (1994), it was noted that while agents seek to self-optimize, they tend not to rely on the self-optimization of others. Thus, in any situation in which there are two different calculations, one of them biased, a trader who recognizes the flaws in the biased reasoning must nevertheless worry that many others could be subject to it, and that there could be a movement toward the prices reflecting the biased reasoning.

The fundamental causes of underreaction are also complex. Practitioners have long noted that investors tend to use reference points to make their decisions. In particular, they are aware of the price at which they purchased the asset and would like to avoid a loss. In this way, they "frame" their decisions and "anchor" potential trades about values such as the purchase price. Kahneman and Tversky (1979) popularized this concept through a series of small experiments where they asked participants questions about their preferences. The two sets of questions were identical in terms of the expected value, but differed only in that one set framed the choice as a loss, while the other framed it as a gain. Extrapolating from this theory (see also Shefrin 2005) suggests that someone who purchased a stock at $\$ 50$ and observed it fluctuating between $\$ 40$ and $\$ 50$ might have an incentive to sell when the price reaches $\$ 50$ once again. Consequently, as the stock moves from $\$ 40$ toward $\$ 50$, a person receiving a signal that the probability of the stock reaching $\$ 60$ is significantly higher would hold if he is evaluating the situation objectively, but sell if he is strongly influenced by the "anchoring" bias. As the price 
reaches $\$ 50$ the trader has the opportunity to avoid a loss, which prospect theory advocates suggest is a strong motivation to trade at $\$ 50$. Hence, one might postulate from prospect theory that "anchoring" is a fundamental cause of underreaction.

In a particular situation, the various behavioral effects can suggest biases that are in different directions. For example, a slightly positive signal on the value of an asset might suggest overreaction through representativeness theory, but underreaction due to prospect theory and anchoring. Distinguishing between the two in market situations is the focus of our research.

In a typical market situation, an asset (e.g. common stock) trades each day and important information (such as an earnings report) is released at the end of the trading day. A significant difference between this situation and the Grether experiments is that continuous trading may have the tendency to establish a price through repetition and reinforcement. This provides an example of "anchoring" in behavioral finance whereby a decision maker focuses on a particular value or set of values and neglects the possibility that the true value is very different from these (Shefrin 2005). In other words, one might expect (based on the Grether experiments) that an update providing a small increase in payout would lead to an over-reaction. However, persistent trading at a low price for an extended period might lead to an under-reaction to the announcement due to anchoring at the lower price that has been established during the trading period. Thus, a dynamical setting rather than a static or two-step process has some additional richness.

While efficient market theorists view the trading price as a harmonious unanimity on the value of the security, many practitioners view it as a tug-of-war between different camps. The small fluctuations about a single value may appear superficially as an equilibrium, but in fact is a tense stalemate that is ultimately resolved, sometimes with a small amount of additional buying or selling arising from new information. It is very common for different large investment houses to offer completely incompatible assessments on everything from stocks to commodities to currencies. However, even as they espouse very different views, they optimize their trading by placing their trades as 
close to the other camp as they are able. In other words, if one investment company values a stock at $\$ 50$ and another at $\$ 100$ while the stock is trading at $\$ 75$, the company trying to buy will not do so at $\$ 100$. They will try to buy as low as possible, namely near $\$ 75$. Hence, a casual observer of the market price will see the price fluctuating close to $\$ 75$, and may conclude, falsely, that there is general agreement among market participants that this is the true value. Thus, an experiment designed to understand market behavior can be made more realistic by giving disparate information to different groups. This can also be used to understand the interaction between the assets of the groups and their assessment of value.

To meet this objective we design a set of experiments in which there are 2 ten minute periods separated by a short break. Participants trade an asset with a single payment occurring at the end of the second period. The traders are classified into two distinct groups receiving different information but trade without the knowledge of other traders' group or information. In the baseline experiments, there is no change in the payout probabilities during the break. In the second set of experiments, however, one or both groups have updated payout expectations that improve the expected payout, thereby matching the payout of the baseline experiments. Hence, the anticipated payout is identical for both groups during the entire second half of the two sets of experiments. In the absence of either under-reaction or over-reaction, there should be no statistical difference between the two treatments. If the second set of experiments has higher trading prices than the baseline treatment, it would suggest over-reaction and be consistent with those studies suggesting that over-reaction will occur. If they are lower than the baseline, it would suggest under-reaction and be consistent with anchoring and framing arguments.

All of the methods of classical finance would imply that there should be no statistical difference in the second period prices (particularly near the end of the second period) between the two treatments. Thus, any difference between the two treatments is attributable to non-classical effects, e.g., under-reaction or over-reaction. Understanding the assimilation of new information is critical to the development of models of market 
dynamics such as the asset-flow approach (Caginalp and Balenovich 1999) which incorporates the concepts of the finiteness of capital as well as fundamental tendency to buy due to the trend as well as the valuation. This approach has been useful in discovering the underlying causes of bubbles in asset market experiments (Caginalp, Porter and Smith 2001).

The rest of this paper is organized as following. Section 2 is a detailed description of the design of the experiment, Section 3 analyzes the results, and Section 4 concludes the paper with some discussions of the results.

\section{Experimental Design}

A single asset was traded using an open-book (traders can observe all bids and asks being offered at any moment) double auction on a computer network. In each experiment, eight to twelve participants are given instructions and a practice session to ensure that they had understood the mechanics of the auction. ${ }^{1}$ Participants in the experiment were evenly and randomly assigned to trader types in the experiment which we will label as Group A and B. Participants were not aware that there were groups, and only knew their own payout information and the history of market prices and transaction volume. In one set of treatments, the groups were differentiated based on the news they received during the experiment. In particular, both groups were informed that the asset traded would have a dividend of either 100 or 10 e-dollars at the end of the experiment. The e-dollars (i.e., experimental dollars that we also denote by E\$) are converted to US dollars at the end of the experiment at a rate that was announced to the participants at the start of the experiment. Each trader is given information (called a "hint") at the beginning of the experiment on the probability of the two payouts. For example, our "hint75" listed on a participant's screen "the payout of the share at the end of the experiment is 100 e-dollars with a chance of $75 \%$ and 10 e-dollars with a chance of $25 \%$ ". Thus, the expected payout for hint75 is $100(75 \%)+10(25 \%)=77.5$ e-dollars. 
The experiment consists of two periods, ${ }^{2}$ lasting 10 minutes each, with a one-minute break in between the periods. During the break news concerning a change in the probability of the dividend payout was provided privately to each participant. In the baseline information treatment, there was no news, so that the initial probability assessments remained the same. The participants in Group A were provided information in the form of hint75 while the Group B participants were given more pessimistic estimates of "hint 25 " -- "the payout of the share at the end of the experiment is 100 edollars with a chance of $25 \%$ and 10 e-dollars with a chance of $75 \%$ "-with an expected payout of 32.5. In one disparate information treatment, news was released at the break between periods to the different groups which involved increasing the probability of the 100 dividend payout. In particular, group A started with "hint60"3 that moved to hint75 and group B started with "hint10", and it moved to hint25. In another information treatment, we had both groups merge to the same probability estimate. In one case, group A started with hint75 and it remained unchanged at the break while group B started with hint 25 and it merged to hint 75 at the break. In a second merge treatment, group A started with hint60 and it moved to hint75 at the break while group B stared at hint10 and merged to hint75 at the break. These information treatments allow us to examine price movements in a variety of information updates.

Previous experiments have demonstrated the strong role of the ratio of cash and number of shares in trading prices (Caginalp, Porter and Smith 1998), which we call liquidity. To ensure robustness of the experimental conclusions, we created some additional treatments varying the share and cash endowments of the two groups. In the equal liquidity treatments, each participant was given the same initial portfolio of 500 edollars and 10 shares or 1000 e-dollars and 10 shares. In our other liquidity treatment we varied the cash to shares ratio of the two groups. One group had more cash (750 in cash a 5 shares) while the other group had the base amount of 500 in cash and 10 shares.

Table 1 summarizes our experimental design of liquidity and information treatments. 


\section{Hypotheses}

The default hypothesis is that, after the midpoint of the experiment, there will be no statistically significant difference between the trading prices in the two sets of experiments, since both experiments consist of the same information after that point. In other words, the default hypothesis that would be suggested by efficient markets is that prices should depend on the available information of expected payout, and not on the price history. However, the key question we will examine is whether there is underreaction or overreaction to the updated information that is injected during the midpoint break of the two periods. Recall that the "Info" sessions have lower expected payout in the first half of the experiment, but are then updated to the same expected payout after the midpoint as the "Base" sessions. If investors underreact to positive information after a prolonged state of lower expectations, then the prices in the information experiments should be lower than the prices in the baseline experiments, namely those in which the information is the same throughout the experiment. Such a result would provide support for the role of anchoring in financial markets and to the concept that price history has a strong effect on future prices even in the face of updated information on fundamental value.

Alternatively, if investors overreact to new information, then the information experiments would have higher prices in the second half than the baseline experiments even though the payout expectations are exactly the same during this latter part of the experiment. This would be consistent with "representativeness" or "affect" whereby participants exaggerate the impact of the new and positive information.

In addition to the fundamental hypotheses, we will also examine the effect of changes in the underlying environment in terms of liquidity. 


\section{Results}

Appendix 1 contains the time series of contact prices for each experimental session. The graphs strongly suggest that there is anchoring in the decision-making of the market participants. There seems to be no evidence of either overreaction to updated market information. To formalize these ocular results, we begin with the following notation:

Pre. $\mathrm{P}_{\mathrm{A}}=$ expected payout by Group A prior to midpoint information update;

Pre. $\mathrm{P}_{\mathrm{B}}=$ expected payout by Group $\mathrm{B}$ prior to midpoint information update;

Post. $\mathrm{P}_{\mathrm{A}}=$ expected payout by Group A after midpoint information update;

Post. $\mathrm{P}_{\mathrm{B}}=$ expected payout by Group $\mathrm{B}$ after midpoint information update;

These are calculated in the usual way by multiplying the probability with the outcome. For example, if Group A is given the hint that there is a $75 \%$ chance of a $\$ 100$ payout and a $25 \%$ chance of a $\$ 10$ payout, then Group $A$ has expected payout of $(0.75)(100)+(0.25)(10)=\$ 77.50$.

The cash endowments of the two groups are denoted by $M_{A}$ or $M_{B}$, and the total number of shares in each group is given by $\mathrm{N}_{\mathrm{A}}$ or $\mathrm{N}_{\mathrm{B}}$. The asset flow differential equations approach and various experiments have shown the importance of the liquidity price per share, computed as the total cash in the system divided by the total number of shares, i.e.,

$$
\mathrm{L}=\frac{M_{A}+M_{B}}{N_{A}+N_{B}}
$$

We first examine the relative impact of these variables on the trading prices in the absence of new information. This can be accomplished by considering price just before the end of the first session (the $10^{\text {th }}$ minute), denoted Pre10. The initial impact of the new information, combined with these variables can be studied by examining prices just after 
the start of the second session, denoted Post10. Finally, one can study the prices just before the end of the experiment (the $20^{\text {th }}$ minute), denoted Pre20, in order to understand how this information is assimilated in time. Since the updated information is presented prior to the start of the second period, a perfectly efficient market would accurately reflect the current outlook. Even if there is some delay in assimilating the new information, however, the effect of the information should be reflected in the prices at the end of the experiment. These questions will be examined through a series of regressions. Since many prices are generated by the same group, we cannot regard them as independent. Consequently, an ordinary linear regression would overstate the statistical confidence. This problem can be overcome by using a fixed effects model that compensates for the dependence of the data on different groups, in this case the experimental sessions (Pinheiro and Bates 2000). Recapitulating the definitions, we have the following:

Pre10: The 9 trading prices just before the end of the first period (at minute 10).

Pre10_1: The previous trading price of Pre10.

Post10: The $2^{\text {nd }}$ to the $10^{\text {th }}$ trading prices just after the start of the second period.

Post10_1: The previous trading prices of Post10.

Pre20: The 9 trading prices just before the end of the second period (at minute 20).

Pre20_1: The previous trading price of Pre20.

Using only the data of the first session, which does not involve any new information, we write,

$$
\log (\operatorname{Pre} 10)=\alpha_{0}+\alpha_{1} \log \left(\operatorname{Pre10} \_1\right)+\alpha_{2} \mathrm{~L}+\alpha_{3} \text { Pre.P } \text { B }_{\mathrm{B}}
$$

After the intercept, the first term is the trading price preceding the final trades in first period which we utilize in order to determine if there is a trend effect at the period end. The second term in the equation will examine whether the liquidity value, L, has a positive coefficient, as expected from previous experimental studies, indicating that price tends to move up as the cash per share ratio in the overall experiment increases. The 
coefficient of the Pre. $\mathrm{P}_{\mathrm{B}}$ term is expected to be positive, which would indicate that the trading price rises as the expected payoff rises (recall that Pre. $P_{B}$ also increases with Pre. $\left.\mathrm{P}_{\mathrm{A}}\right)$. First we calculate the logarithm of all prices, and then control for the session as a random effect, and we perform the regression using the SPlus fixed effects model on (2). Table 2 provides the estimates of our model.

As expected, the coefficients of both $\mathrm{L}$ and Pre. $\mathrm{P}_{\mathrm{B}}$ are positive, and significant. We find no support for any trend (coefficient of $\log \left(\operatorname{Pre} 10 \_1\right)$ as prices have essentially settled almost ten minutes after the start of trading.

Next, we focus on the impact of the new information that is released in between the first and second periods for some of the treatments. We let INFO denote the indicator variable that equals 1 when there is information leading to an upgrade of the expected payout, and zero otherwise. A fixed effects linear regression analysis is then performed for the trading price just after the second session starts, i.e., Post10. The fixed effects mode we estimate is:

$$
\log (\text { Post } 10)=\alpha_{0}+\alpha_{1} \log (\text { Post10_1 })+\alpha_{2} L+\alpha_{3} \text { INFO }+\alpha_{4} \text { Post.P } P_{B}
$$

Table 3 contains the estimates of this model.

In addition to this initial reaction to the new information, one can examine the final trades of the experiment to determine whether the underreaction that is evident immediately after the announcement is remedied. This yields the regression model and results:

$$
\text { Log.Pre } 20=\alpha_{0}+\alpha_{1} \log (\text { Pre20_1 })+\alpha_{2} L+\alpha_{3} \text { INFO }+\alpha_{4} \text { Post.P }{ }_{B}
$$

As indicated by Table 4, the regression shows that there is a significant negative coefficient for INFO, indicating that experiments in which the expectation was lower for one or both groups corresponded to lower prices near the end of the experiment even though the expectations were identical in the second half. This suggests that the under- 
pricing observed during the initial part of the second period persist until the end of the experiment.

\section{Conclusions}

We have conducted a series of experiments in which participants trade an asset that has a single payout at the end of two periods of ten minutes each. In some of the experiments the information given to some or all traders was updated at the end of the first ten minute period, while it was left unchanged in other experiments. The experiments also differed in terms of the cash to asset level of participants (liquidity levels). Previous work has shown that the liquidity is an important factor in determining trading prices, so a range of liquidity levels were used for robustness.

The data has been analyzed using a series of mixed effects regressions that compensate for heteroskedasticity, or the fact that many data points are generated by the same group. The first regression concerns only the first period, entailing no new information during the time period analyzed. Each of the nine prices at the end of this first period is regressed against the expected payout, the liquidity and the previous trading price. As expected, the trading prices increase with increasing expected payout and liquidity. These are highly significant statistically with p-values of 0.0045 and 0.0015 respectively. The dependence on the previous trading price is not significant. Although it was expected from our previous results, the role of liquidity remains strong even after much trading has occurred, suggesting that it is not due to initial confusion or lack of familiarity with the trading system.

The next regression explores the impact of new information by examining the dependence of the first nine trades of the second period on the payout, liquidity and previous price, plus the dummy variable (INFO) that is defined as 1 if there is new information and 0 if there is none. The INFO variable is highly significant, with a p-value of 0.0047. The negative value indicates that those experiments in which the information was updated exhibited lower trading prices during the second half compared to the experiments in which the information remained the same. Two sets of experiments featuring identical expected payout during the second half nevertheless differ in terms of trading price depending on the conditions that prevailed in the first half. Hence, the lower 
trading price observed in the experiments featuring a more subdued past demonstrates a strong deviation from any concept of optimization (e.g., Bayesian) that utilizes only current information.

The issue of whether these lower trading prices are transient is examined in the subsequent regression that differs from the previous one in that we utilize the last nine trades of the second period. Using identical independent variables we find results that are quite similar, indicating that the lower prices resulting from the lower expectations of the first period are persistent in time. In fact, the INFO variable is still negative and even larger in magnitude. The main difference between the two sets of regressions (first versus last nine trades of the second period) is that the role of liquidity and the expected payout are both larger at the end of the experiment. It is not entirely surprising that some time is required for traders to assimilate the expected payout. However, one may have predicted that the role of liquidity would diminish as traders have more time to consider the expected payout. The result that the impact of liquidity increases with time suggests a deeper role for liquidity. In particular, as the trading evolves, the fact that there are more dollars chasing the same number of shares tends to influence how people place their bids and asks. A higher liquidity level means that there are more dollars with which one can bid, thereby raising the price that in turn influences others to raise their bids and asks. The fact that there is a significant trend term during the initial trades of the second period suggests that rising prices influence trading decisions. The trend term is not significant during the last nine trades by which time the price has settled. The asset flow used by Caginalp and collaborators since 1989 has indicated a complex relationship between the trend, the past history of prices and valuations and current valuations. The positive trend term in the initial trades of the second period is consistent with the expectations of this theory. In particular, consider the experiments in which one of the groups receives updated information while the other does not. The group receiving no new information has the same expected payout, but notices rising prices that indicate that perhaps others have information upgrading the payout, and react by bidding higher for the asset.

A number of the questions arising have the potential to be addressed by additional asset market experiments. With a larger number of experiments that differ only in the distribution of assets among groups (defined as receiving or not receiving updated 
information) one can hope to obtain enough data to understand the motivations underlying the higher prices. A pilot experimental study on these questions was performed in Caginalp (2002) where the asymmetric information was given to three groups of participants with varying levels of cash. While trading prices reflected the additional information given to just one of the three groups, a large amount of additional cash led to prices that were much higher than could be expected even with all of the information. This leads to a number of questions. If information is received by only some of the participants what is the mechanism whereby the market assimilates that information? Does the price reach the level that it would if all participants received the information? What is the time scale on which the new equilibrium (or steady state) price is reached and how does it depend on the fraction of assets owned by the group receiving the new information?

In summary, our statistical analysis provides support for the assertion that market prices underreact to information that upgrades an expected payout following a prolonged period of less positive information and prices. This means that the price (when adjusted for the other variables such as liquidity) is lower in the experiments featuring an upgrade of the payout than it is for the experiments having the higher expected payout from the start. Furthermore, this underreaction persists throughout the remainder of the experiment, providing support for the concept of anchoring in asset price dynamics. If fundamentals and trading prices are low for a prolonged time, then improvement of fundamentals does not lead to the same price that would be attained if the fundamentals were always high. In other words, the market price in our experiments is not simply a function of the current expectations, as efficient market theory and classical economics would predict. But rather, the trading price depends strongly on the past price history of the asset. Even in this experimental setting where the fundamentals are clearer than they are in field markets, participants appear to be influenced by either the lower price or the lower fundamentals of the past. On a practical level, this study provides some support to value managers who claim that bargains among out-of-favor stocks persist for some time.

The findings of under-reaction - possibly as a consequence of anchoring - appear, at first glance, to be in contrast to the Grether experiments where an update providing a small increase in payout leads to an over-reaction. One factor that distinguishes the two 
types of experiment is time. In the two-step experiment of Grether, the new information is only the second piece of information, and there has been no opportunity to observe others' reactions in the intervening time. In our experiments, there is a significant amount of time and trading that occurs prior to the release of the new information. It is possible that there is some tendency for over-reaction to the new information that is much smaller than a competing tendency for under-reaction that is caused by the nature of trading. In other words, when the updated information (suggesting a higher payout) is released at the start of the second half of our experiments, some traders may react in accordance with representativeness rather than Bayesian strategy and be prone to overreacting. However, others may be focusing on the trading that has occurred, and remain skeptical of the new information. If the latter dominate during the initial trades of the second period, then traders who initially were prone to over-reacting may be readjusting their strategy in light of the information on others' strategies obtained through observing the trading prices. Undoubtedly, the effect of over-reaction to new information (due to representativeness) observed by Grether is present in our experiments; however, other factors leading to under-reaction appear to be stronger under the conditions of our experiments. Thus, one might regard under-reaction and over-reaction as competing effects, just like stability and instability, with the winner of the competition depending on many factors that are yet to be discovered.

One of these factors may be closely related to prospect theory. Behavioral finance has shown that decision makers treat potential losses differently from gains. When the news upgrades the payout at the midpoint of the experiment, there is the possibility of greater profits for those who wish to purchase more of the asset. However, failure to do so will not lead to loss. At this point in the experiment, the participants have come to regard the current value of the stock plus cash as their own. By not rushing to buy more shares, they are not losing any money that they have become accustomed to regarding as their own. It is possible that with short selling or selling of futures contracts there would be some traders scrambling to cover their shorts and bidding up prices aggressively. This could be a source of over-reaction. 
Ultimately, the issues of under-reaction and over-reaction are at the heart of behavioral finance. If these effects did not exist in a statistically verifiable sense, then there would be no change in the trading price due to behavioral effects, and the classical paradigm would be realized. Moreover, if the effects of under-reaction and over-reaction cannot be distinguished a priori even with the comprehensive information that we have in asset experiments, then it would be difficult to build behavioral finance into a quantitative and predictive science. Thus, developing an understanding of the conditions that lead to under-reaction and over-reaction, respectively, is an essential step in understanding the motivations that underlie non-classical behavior in finance. 


\section{REFERENCES}

Beard, T. and R. Beil. 1994. Do people rely on the self-interested maximization of others? An experimental test. Management Science 40: 252-262.

Caginalp, G. 2002. Does the market have a mind of its own, and does it get carried away with excess cash? J. Psychology and Financial Markets 3: 72-75.

Caginalp, G. and Balenovich, D. 1999. Asset flow and momentum: Deterministic and stochastic equations. Philosophy Trans. R. Soc. 357: 2119-2133.

Caginalp, G., D. Porter, and V. Smith.1998. Initial cash/asset ratio and asset prices: An experimental study. Proceedings of the National Academy of Sciences 95: 756761.

Caginalp, G., D. Porter, and V. Smith. 2001. Financial Bubbles: Excess Cash, Momentum and Incomplete Information. J. Psychology and Financial Markets 2: 80-99.

Grether, D. 1980. Bayes rule as a descriptive model: The representative heuristic. Quarterly Journal of Economics 95: 537-557.

Kahneman, D. and A. Tversky, 1979. Prospect theory: An analysis of decision making under risk. Econometrica 263-291.

Pinheiro, J. and D. Bates. 2000. Mixed Effects Models in S and S-Plus. New York: Springer Verlag.

Pontiff, J. 1997. Excess volatility of closed-end funds. American Economic Review 87: $155-167$. 
Shefrin, H. 2005. A Behavioral Approach to Asset Pricing. SanDiego: Elsevier.

Shiller, R. 1981. Do stock prices move too much to be justified by subsequent changes in dividends? American Economic Review 75: 1071-1082.

Slovic, P., M. Finucane, E. Peters, and D. MacGregor. 2002. Risk as analysis and risk as feelings: Some thoughts about affect, reason, risk and rationality. Risk Analysis 24(2):

Smith, V.L., G.L. Suchanek, and A.W. Williams. 1988. Bubbles, crashes, and endogenous expectations in experimental spot asset markets. Econometrica 56: 1119-1151.

Weber, M. and C. Camerer. 1998. The disposition effect in securities trading. Journal of Economic Behavior and Organization 33:167- 184. 


\section{FOOTNOTES}

${ }^{1}$ The experimental instructions can be found in the Appendix 2.

${ }^{2}$ The dividend was realized after period 2.

${ }^{3}$ The message for hint60 was "the payout of the share at the end of the experiment is 100 e-dollars with a chance of $60 \%$ and 10 e-dollars with a chance of $40 \%$ "

4 "the payout of the share at the end of the experiment is 100 e-dollars with a chance of $10 \%$ and 10 e-dollars with a chance of $90 \% "$ 
Table1: Experimental Design

\begin{tabular}{|c|c|c|c|c|c|c|}
\hline \multirow{2}{*}{$\begin{array}{r}\text { Session } \\
\text { Identifier }\end{array}$} & \multirow{2}{*}{$\begin{array}{l}\begin{array}{c}\text { Number } \\
\text { of }\end{array} \\
\text { Sessions }\end{array}$} & & \multicolumn{2}{|c|}{$\begin{array}{c}\text { Liquidity } \\
\text { Treatment }\end{array}$} & \multicolumn{2}{|c|}{$\begin{array}{l}\text { Information } \\
\text { Treatment* }\end{array}$} \\
\hline & & Group & $\begin{array}{l}\text { Cash } \\
\text { Amount }\end{array}$ & $\begin{array}{r}\text { \# of } \\
\text { Shares }\end{array}$ & in 1st period & $\begin{array}{l}\text { in 2nd } \\
\text { period }\end{array}$ \\
\hline \multirow[t]{2}{*}{ Base_1 } & \multirow[t]{2}{*}{3} & $\mathrm{~A}$ & 500 & 10 & hint75 & hint 75 \\
\hline & & B & 500 & 10 & hint 25 & hint 25 \\
\hline \multirow[t]{2}{*}{ Base_2 } & \multirow[t]{2}{*}{3} & A & 750 & 5 & hint75 & hint 75 \\
\hline & & B & 500 & 10 & hint 25 & hint 25 \\
\hline \multirow[t]{2}{*}{ Base_3 } & \multirow[t]{2}{*}{3} & A & 500 & 10 & hint75 & hint 75 \\
\hline & & $\mathrm{B}$ & 750 & 5 & hint 25 & hint 25 \\
\hline \multirow{2}{*}{ Base_4 } & \multirow[t]{2}{*}{2} & A & 1000 & 10 & hint75 & hint 75 \\
\hline & & B & 1000 & 10 & hint 25 & hint 25 \\
\hline \multirow[t]{2}{*}{ Info_1 } & \multirow[t]{2}{*}{3} & A & 500 & 10 & hint60 & hint75 \\
\hline & & B & 500 & 10 & hint 10 & hint 25 \\
\hline \multirow[t]{2}{*}{ Info_2 } & \multirow[t]{2}{*}{3} & A & 750 & 5 & hint60 & hint75 \\
\hline & & $\mathrm{B}$ & 500 & 10 & hint10 & hint 25 \\
\hline \multirow[t]{2}{*}{ Info_3 } & \multirow[t]{2}{*}{3} & A & 500 & 10 & hint60 & hint75 \\
\hline & & $\mathrm{B}$ & 750 & 5 & hint 10 & hint 25 \\
\hline \multirow[t]{2}{*}{ Info_4 } & \multirow[t]{2}{*}{1} & A & 1000 & 10 & hint60 & hint75 \\
\hline & & B & 1000 & 10 & hint 10 & hint 25 \\
\hline \multirow[t]{2}{*}{ Merge_1 } & \multirow[t]{2}{*}{3} & A & 500 & 10 & hint75 & hint75 \\
\hline & & $\mathrm{B}$ & 500 & 10 & hint 25 & hint 75 \\
\hline \multirow[t]{2}{*}{ Merge_2 } & \multirow[t]{2}{*}{3} & A & 500 & 10 & hint60 & hint75 \\
\hline & & $\mathrm{B}$ & 500 & 10 & hint 10 & hint 75 \\
\hline
\end{tabular}

Caption: To read the table, "Base_1" features an endowment $\$ 500$ (e-dollars) and 10 shares for both groups: "Base_2" endowed Group A with $\$ 750$ and 5 shares, while Group B was endowed with $\$ 500$ and 10 shares. All the four "Info" treatments have the same endowments with their corresponding "Base" treatments, but instead of having the same hints throughout the whole experiment, "Info" treatments updated the subjects during the midpoint break with higher expected payout for the second session. Comparing "Info_1" and "Base_1" we note that each has exactly the same endowments, but "Info_1" initially gives Group A "hint60," with expected payout 100(.6)+10(.4)=64, and gives Group B "hint10," with expected payout 100(.1)+10(.9)=19. During the midpoint break, Group A was updated with "hint75," and Group B was updated to "hint25," i.e., the same level of expected payouts as in the "Base_1" treatment.

*hint75: The payout is 100 with probability=75\%, 10 with probability $=25 \%$; hint25: The payout is 100 with probability $=25 \%, 10$ with probability $=75 \%$; hint60: The payout is 100 with probability $=60 \%$, 10 with probability $=40 \%$; hint10: The payout is 100 with probability $=10 \%, 10$ with probability $=90 \%$. 
Table 2: Regression Estimates

(Number of Observations $=243$; Number of Groups $=27)$

\begin{tabular}{|l|c|c|c|c|c|}
\hline & Value & Std.Error & DF & t-value & p-value \\
\hline (Intercept) & 2.119391 & 0.2948915 & 215 & 7.187018 & $<.0001$ \\
\hline LOG(Pre10_1) & 0.037886 & 0.0661349 & 215 & 0.572854 & 0.5673 \\
\hline L & 0.009439 & 0.0026394 & 24 & 3.576149 & 0.0015 \\
\hline Pre.P & 0.022961 & 0.0073149 & 24 & 3.138894 & 0.0045 \\
\hline
\end{tabular}

Caption: The table contains the estimates of the fixed session effects regression in which the log price of the first ten contracts after the information update is considered dependent on a fixed amount, plus the log of ten contract prices prior to the update, plus the level of liquidity in the market and the expected payout to group B prior to the update. Both liquidity and the initial payout are positive and significant as predicted, but there is no trend effect given that contract prices prior to the update have no significant effect. 
Table 3: Regression Estimates with Information Dummy

$($ Number of Observations $=243$; Number of Groups $=27)$

\begin{tabular}{|c|c|c|c|c|c|}
\hline & Value & Std.Error & DF & t-value & p-value \\
\hline (Intercept) & 1.824148 & 0.2526954 & 215 & 7.218765 & $<.0001$ \\
\hline LOG(Post10_1) & 0.424578 & 0.0529105 & 215 & 8.024457 & $<.0001$ \\
\hline L & 0.004093 & 0.0018865 & 23 & 2.169859 & 0.0406 \\
\hline INFO & -0.21126 & 0.0674154 & 23 & - & 0.0047 \\
\hline Post.Pb & 0.003218 & 0.0020059 & 23 & 1.604100 & 0.1223 \\
\hline
\end{tabular}

Caption: The log of first 10 contract prices after the information is regressed, using fixed effects on experimental sessions, against the trend represented by the log of the 10 contract prices prior to the information update. In addition, liquidity as measured by total cash to total shares, along with an information dummy to capture an information event that increases the expected payout and the initial expected payout of group B. As in the previous tables, liquidity and initial payout expectations are positive and significant while the trend is not significant. Information has a significant negative effect suggesting an underreaction to information. 
Table 4: Regression Estimates

$($ Number of Observations $=243$; Number of Groups $=27)$

\begin{tabular}{|c|c|c|c|c|c|}
\hline & Value & Std. Error & DF & t-value & p-value \\
\hline (Intercept) & 2.530798 & 0.5400523 & 215 & 4.686210 & $<.0001$ \\
\hline $\log ($ Pre20_1) & -0.006639 & 0.0653174 & 215 & -0.101643 & 0.9191 \\
\hline L & 0.011170 & 0.0050320 & 23 & 2.219718 & 0.0366 \\
\hline INFO & -0.326043 & 0.1757902 & 23 & -1.854727 & 0.0765 \\
\hline Post.P & 0.012929 & 0.0054016 & 23 & 2.393592 & 0.0252 \\
\hline
\end{tabular}

Caption: The log of first 10 contract prices after the information is regressed, using fixed effects on experimental session, against the trend represented by the log of the 10 contract prices prior to the information update. In addition, liquidity as measured by total cash to total shares, along with an information dummy to capture an information event that increases the expected payout and the initial expected payout of group B. As in the previous tables, liquidity and initial payout expectations are positive and significant while the trend is not significant. Information has a significant negative effect suggesting an under reaction. Prices at the end of period 2 reflected in the $\log$ of the prices prior to the last 10 trading prices in period 2 is not significant. This suggests that underreaction has not been remedied after the information amount. The results from Table 4 suggest that the overreaction is persistent over the entire second period. 
Appendix 1: Time Series of Contract Prices per Session 

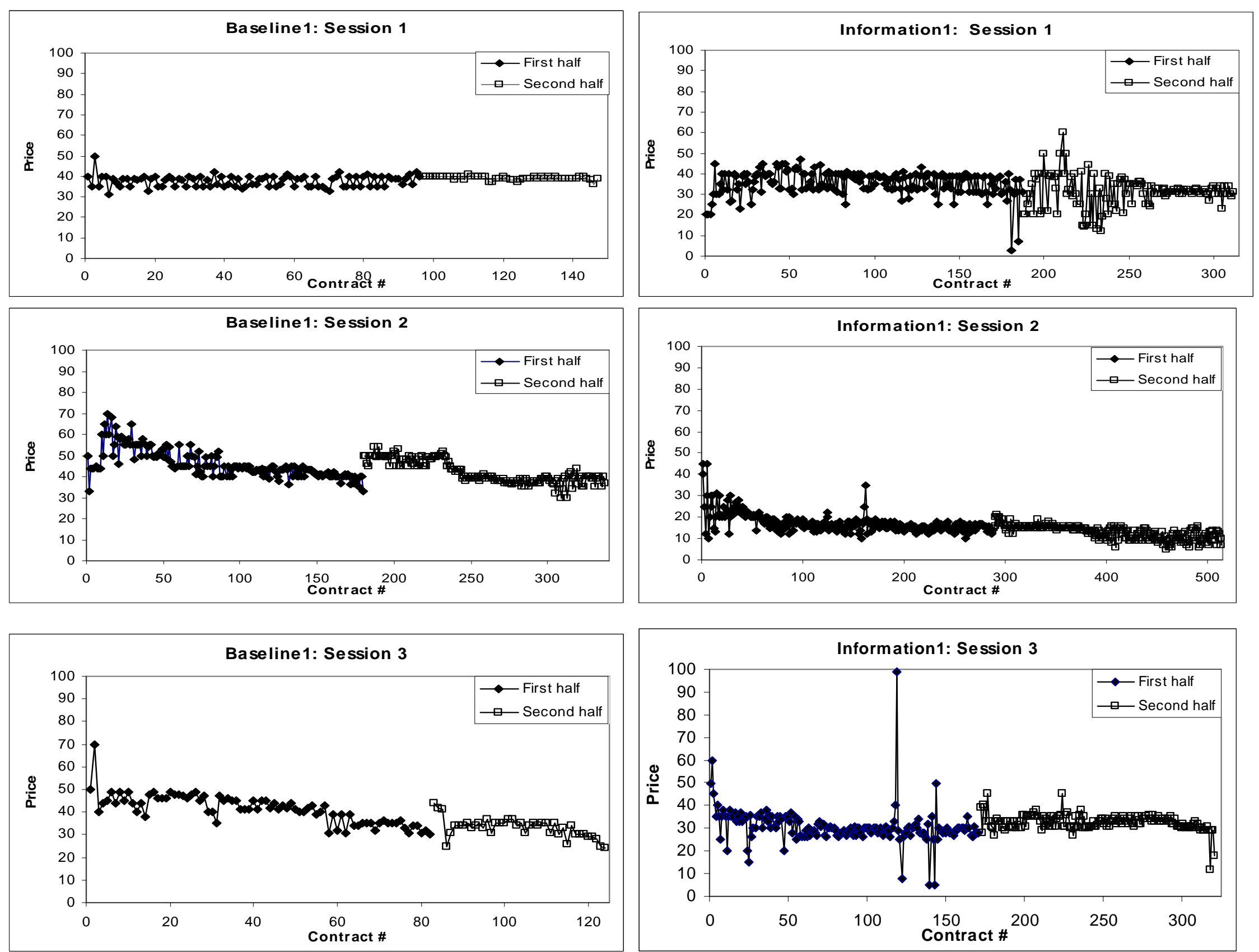

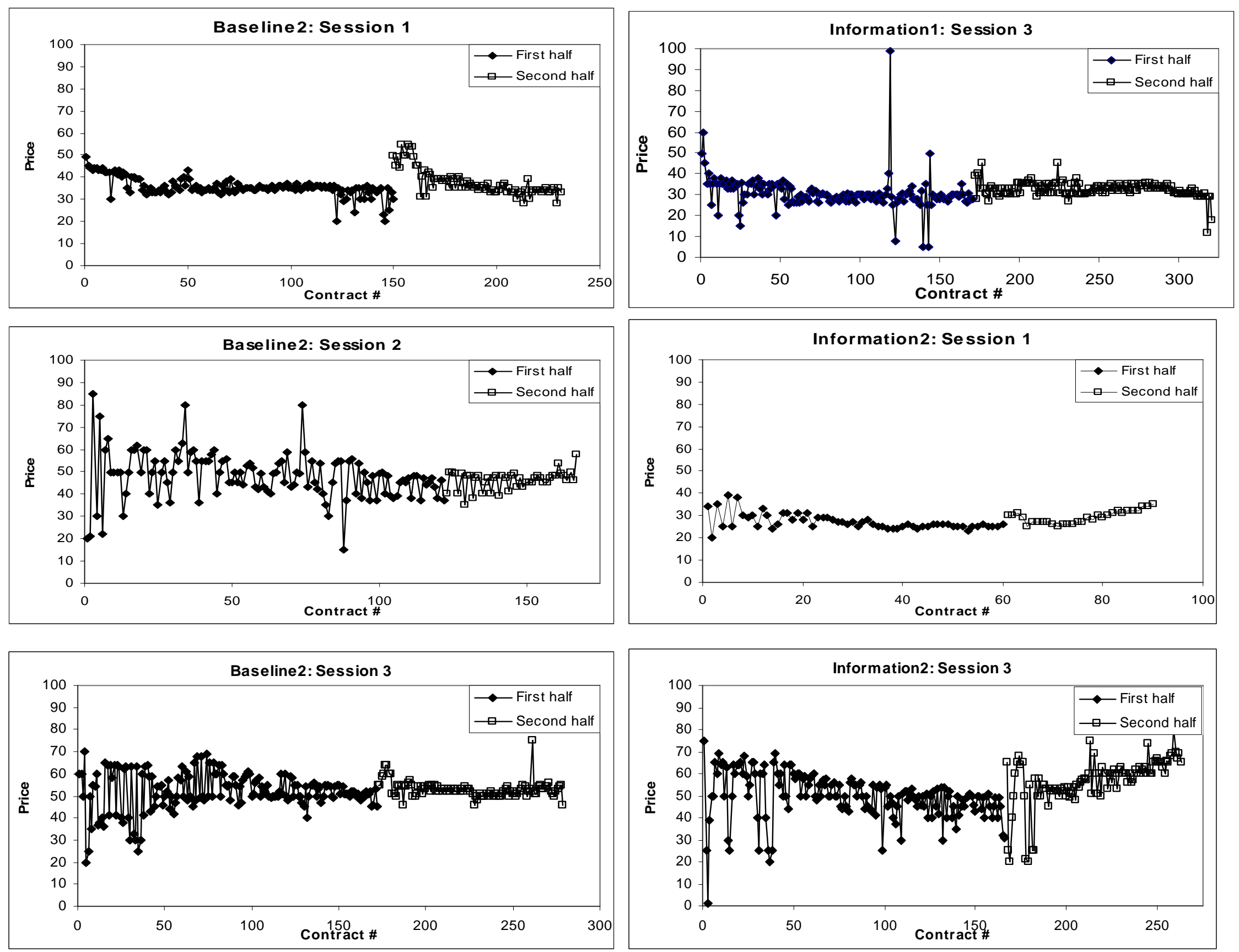

Page 28 of 50 

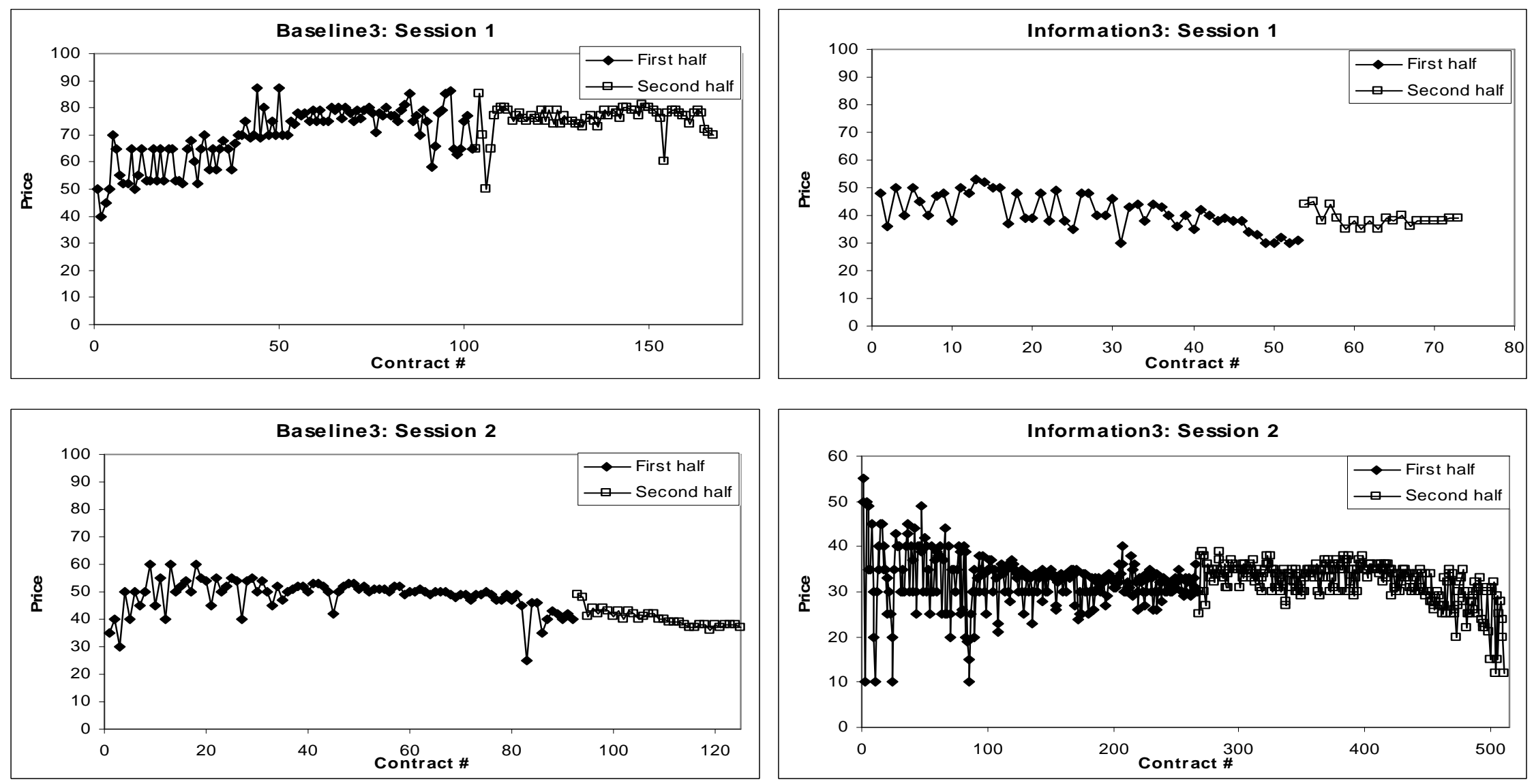

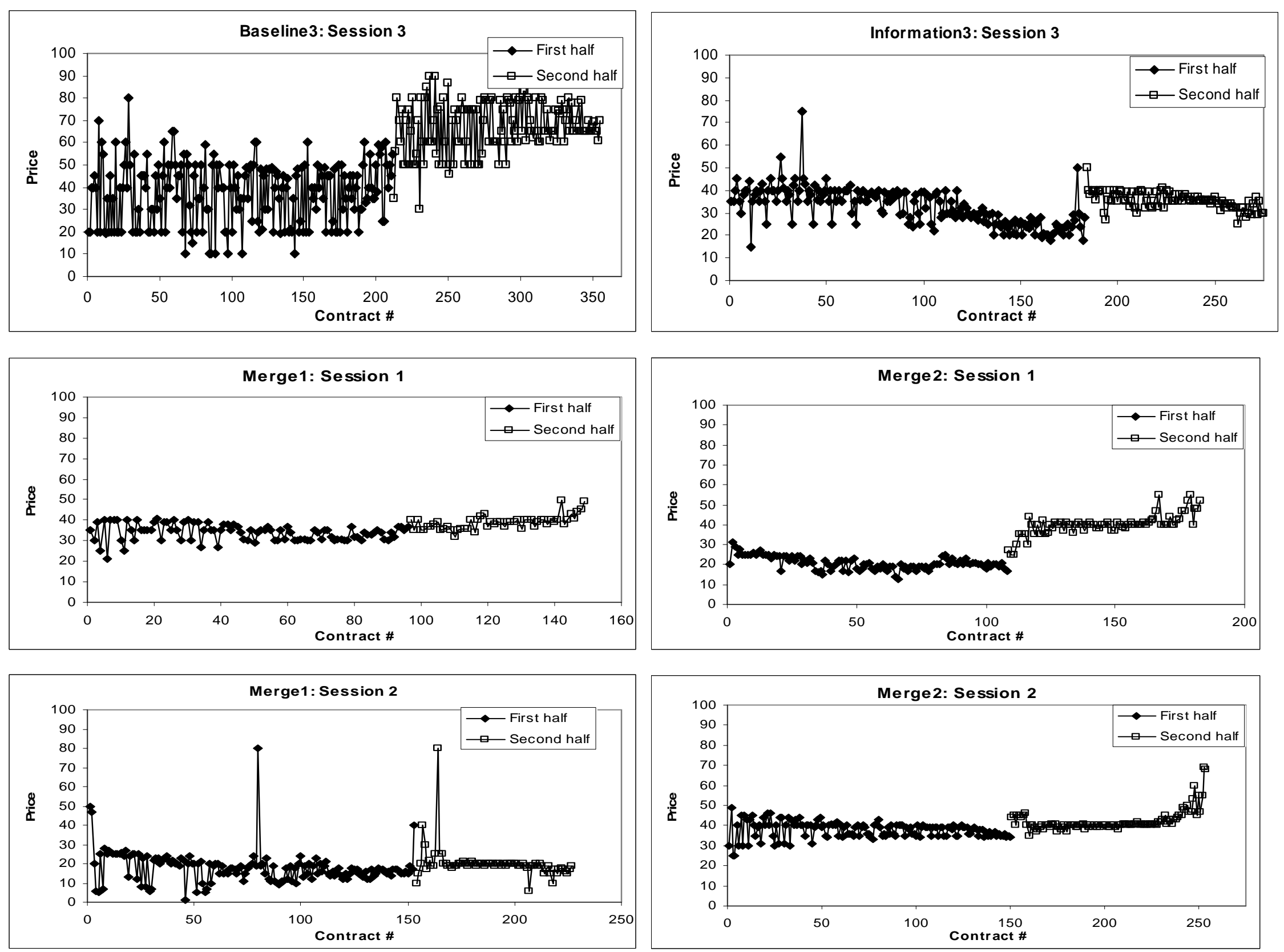

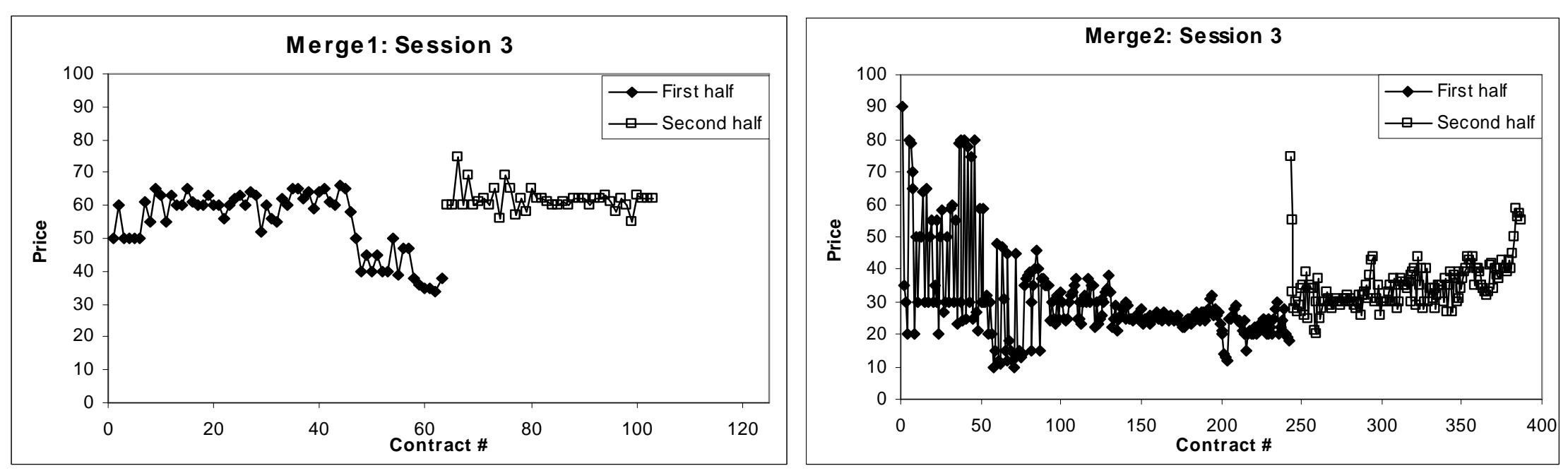

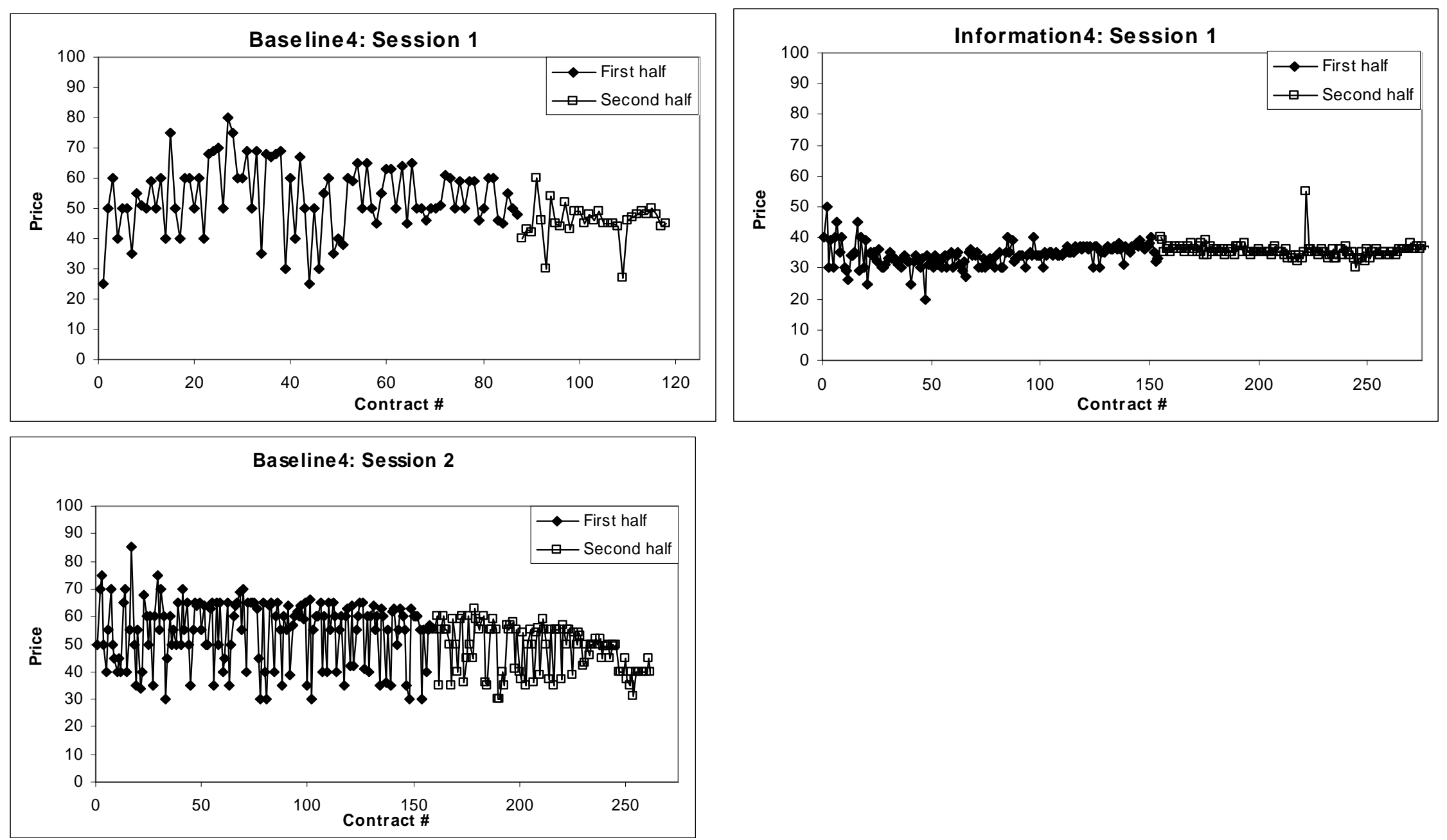


\section{Appendix 2}

\section{INSTRUCTIONS}

This is an experiment in market decision making, and you will be paid for you participation in cash, at the end of the experiment.

Different participants may earn different amounts. What you earn depends on your decisions and the decisions of others.

The experiment will take place through computer terminals at which you are seated. We will start with a detailed instruction period. During the instruction period, you will be given a complete description of the experiment and will be shown how to interact with the computers.

If you have any questions during the instruction period, raise your hand and your question will be answered so everyone can hear. If any difficulties arise after the experiment has begun, raise your hand, and a monitor will come and assist you.

Next PRESS NEXT TO CONTINUE 


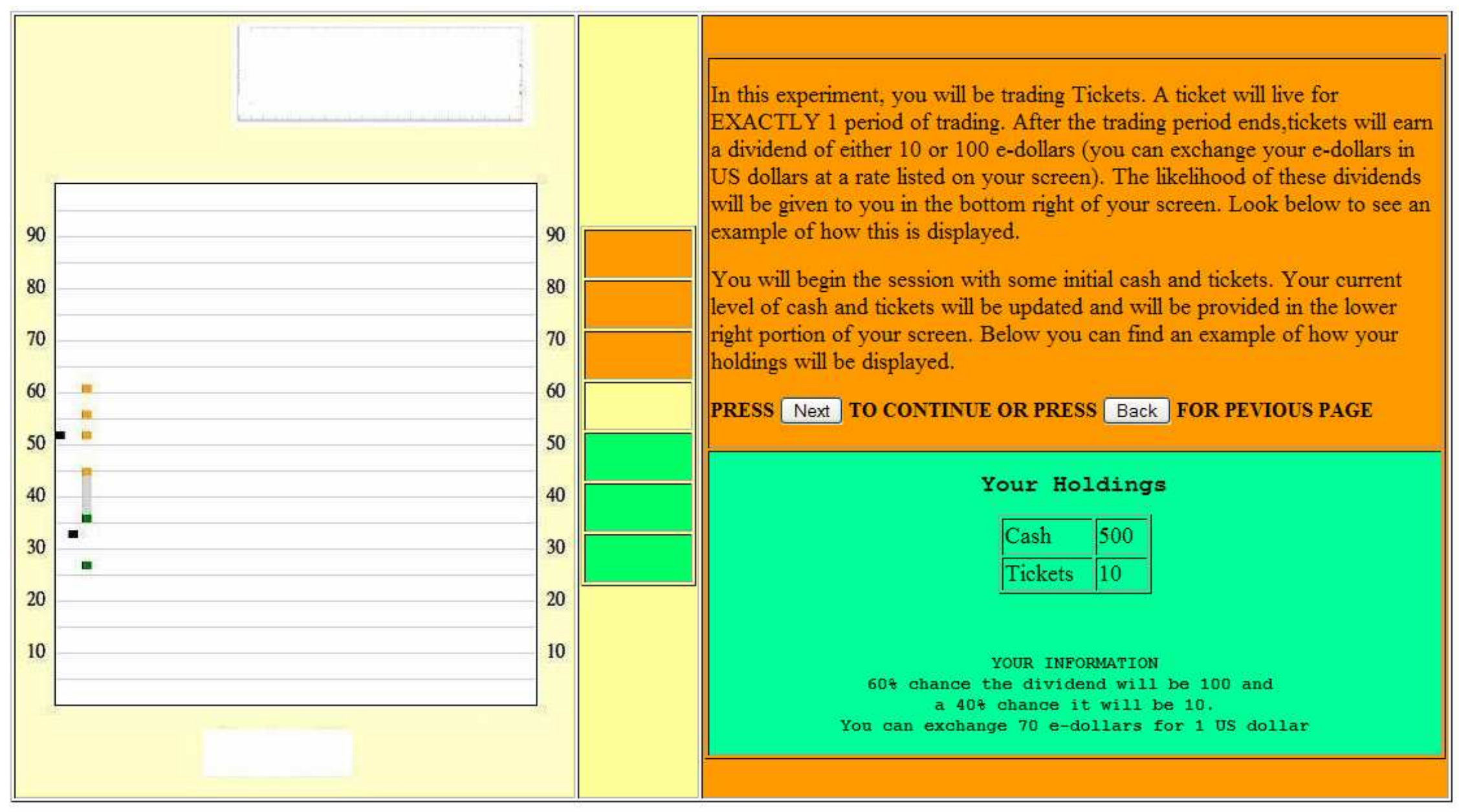

Page 34 of 50 


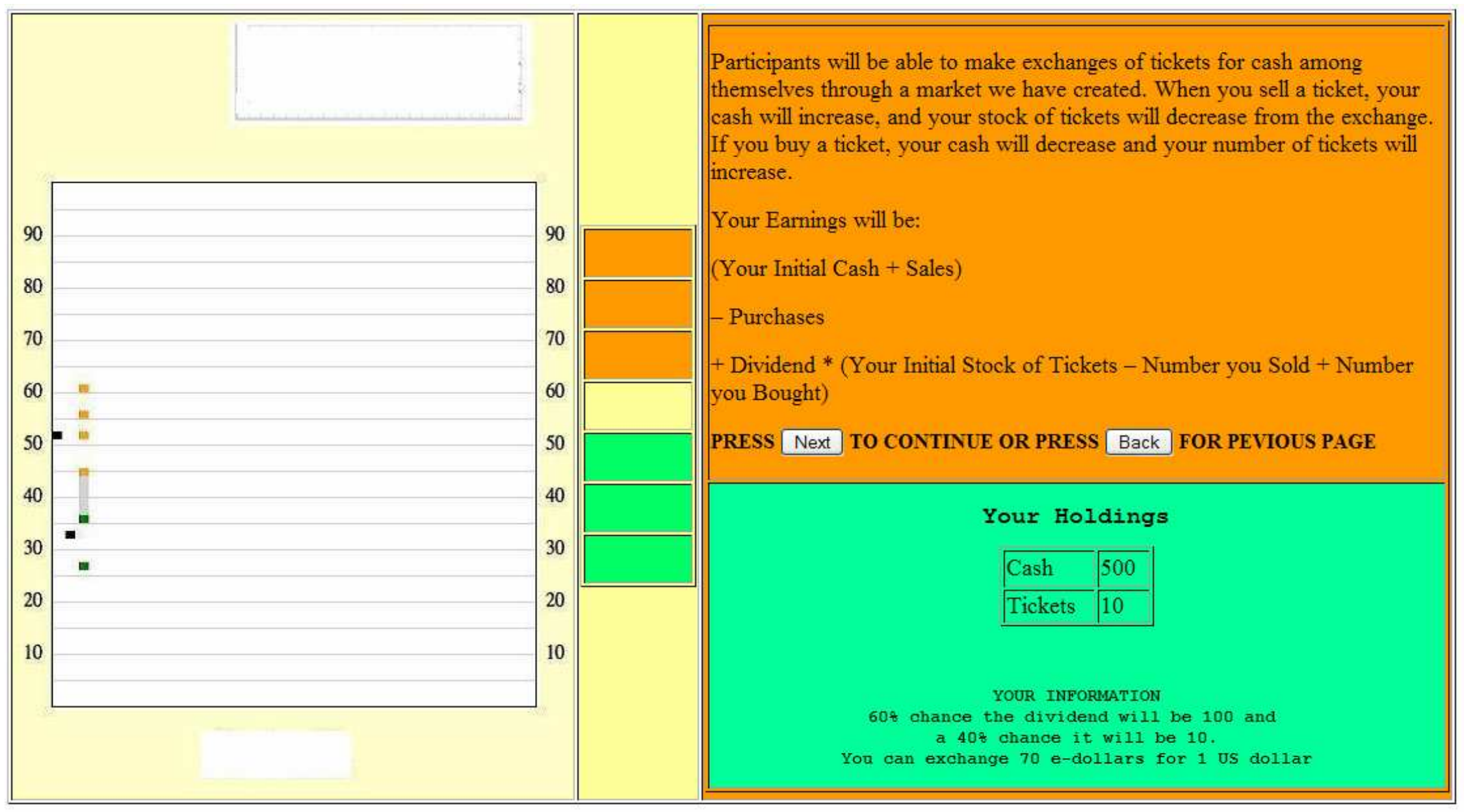

Page 35 of 50 


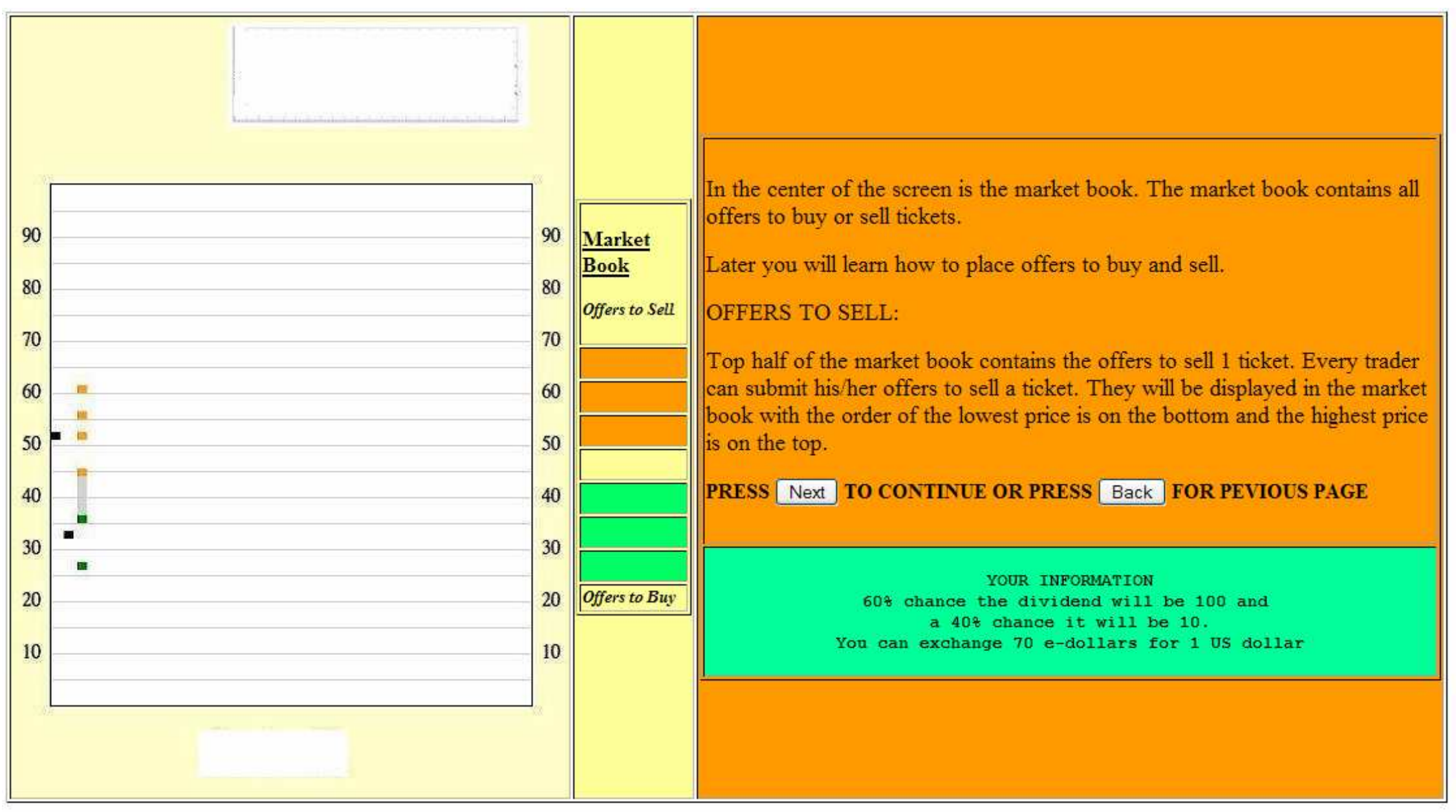




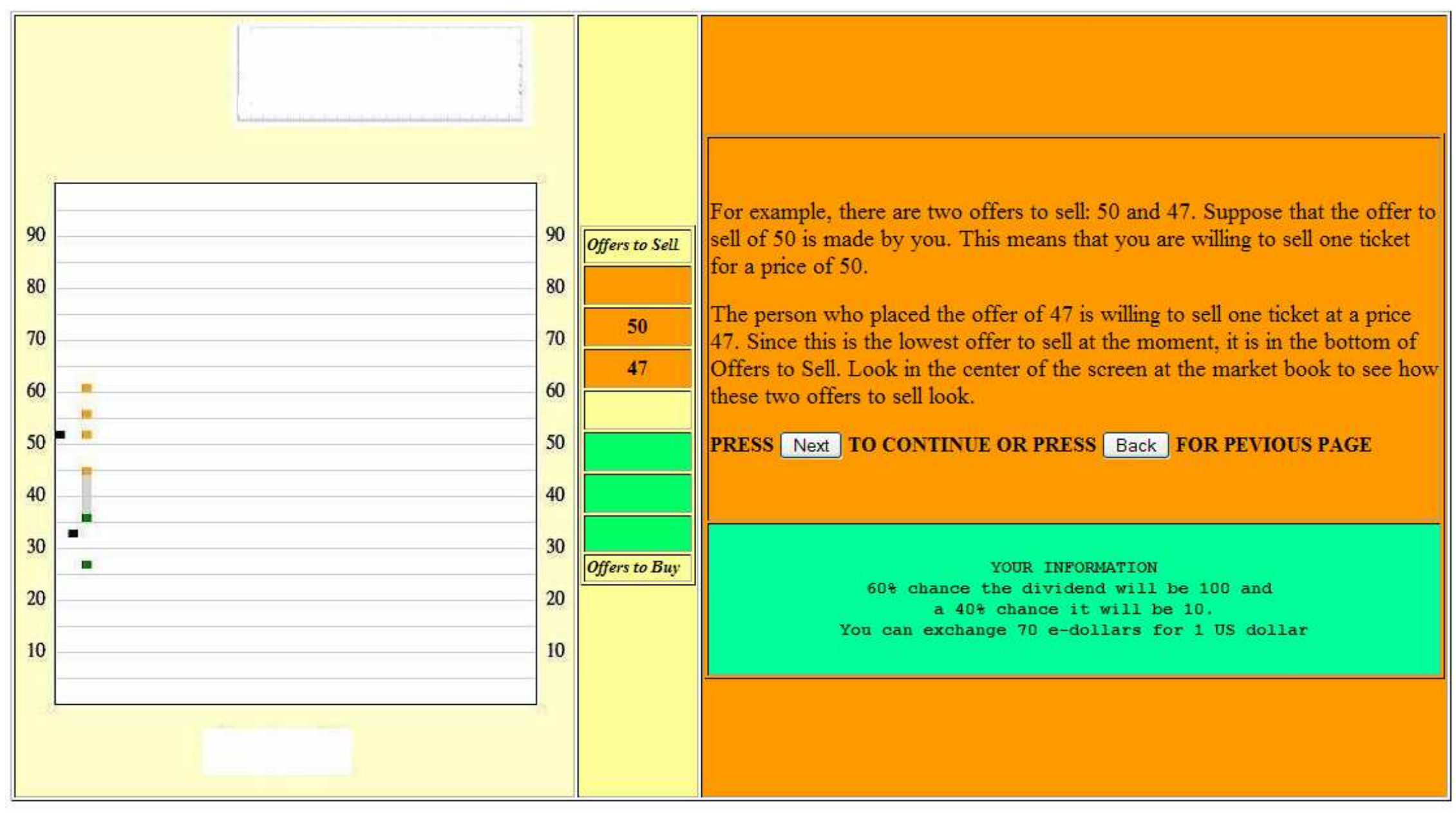

Page 37 of 50 


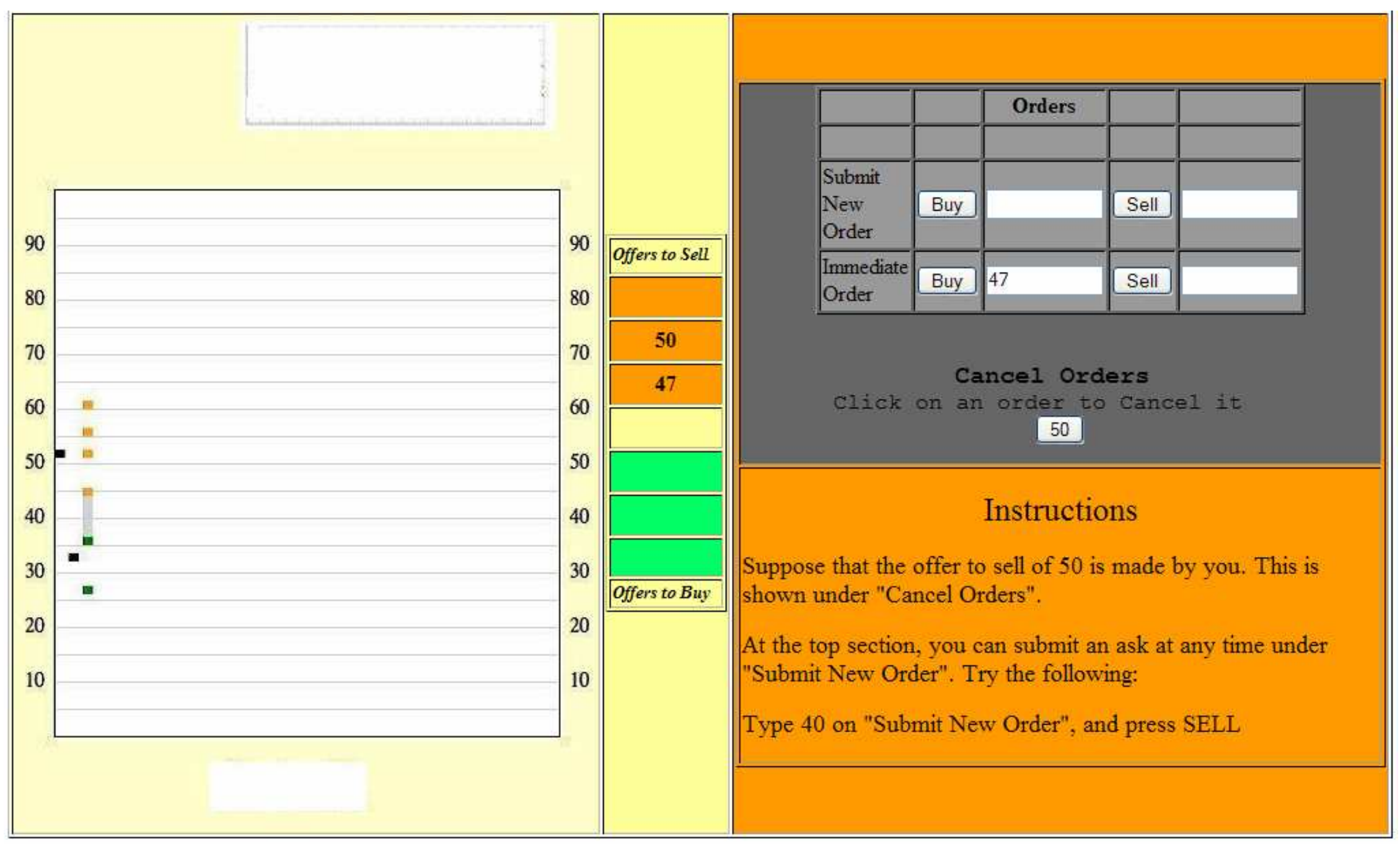

Page 38 of 50 


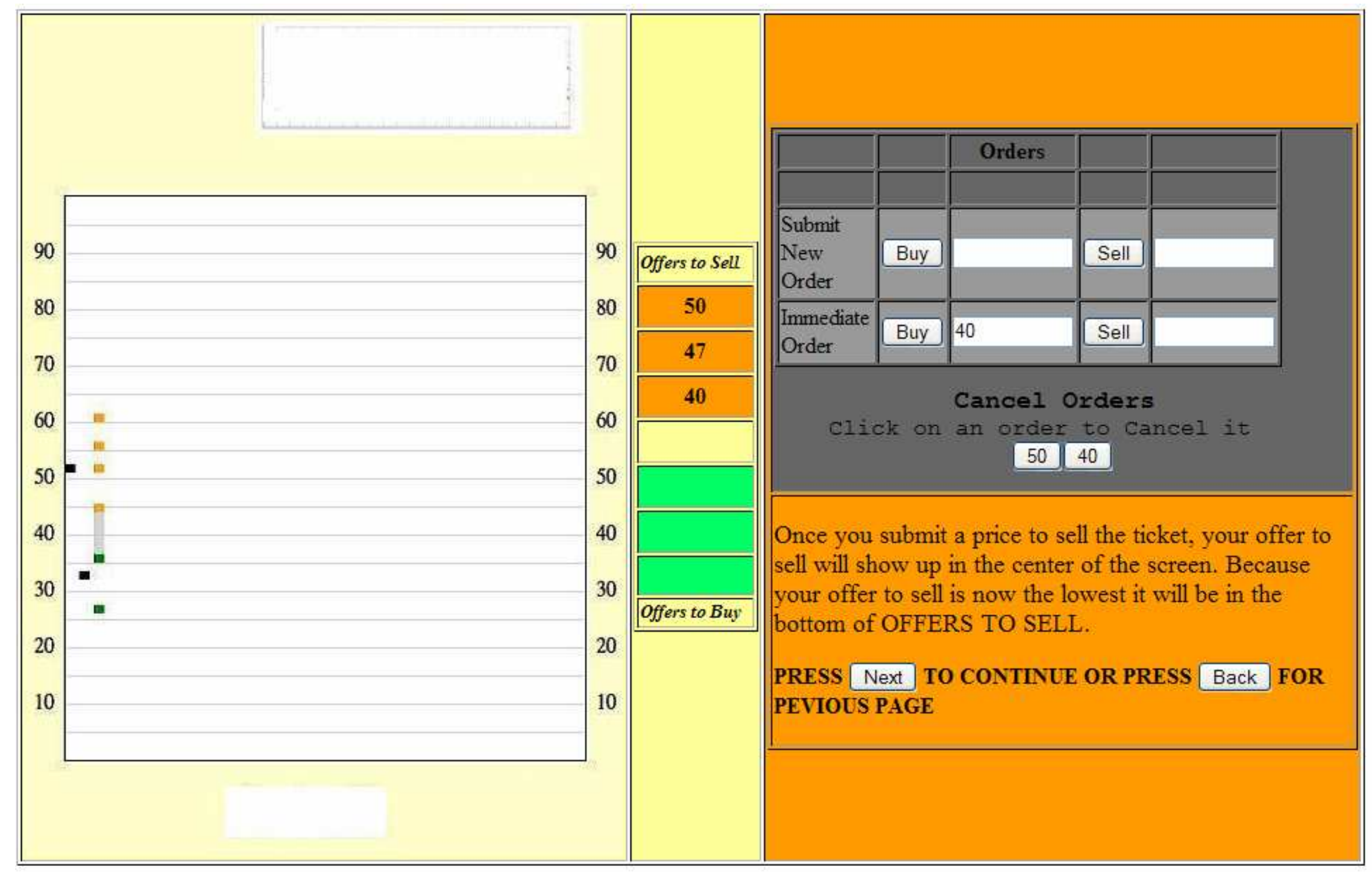

Page 39 of 50 


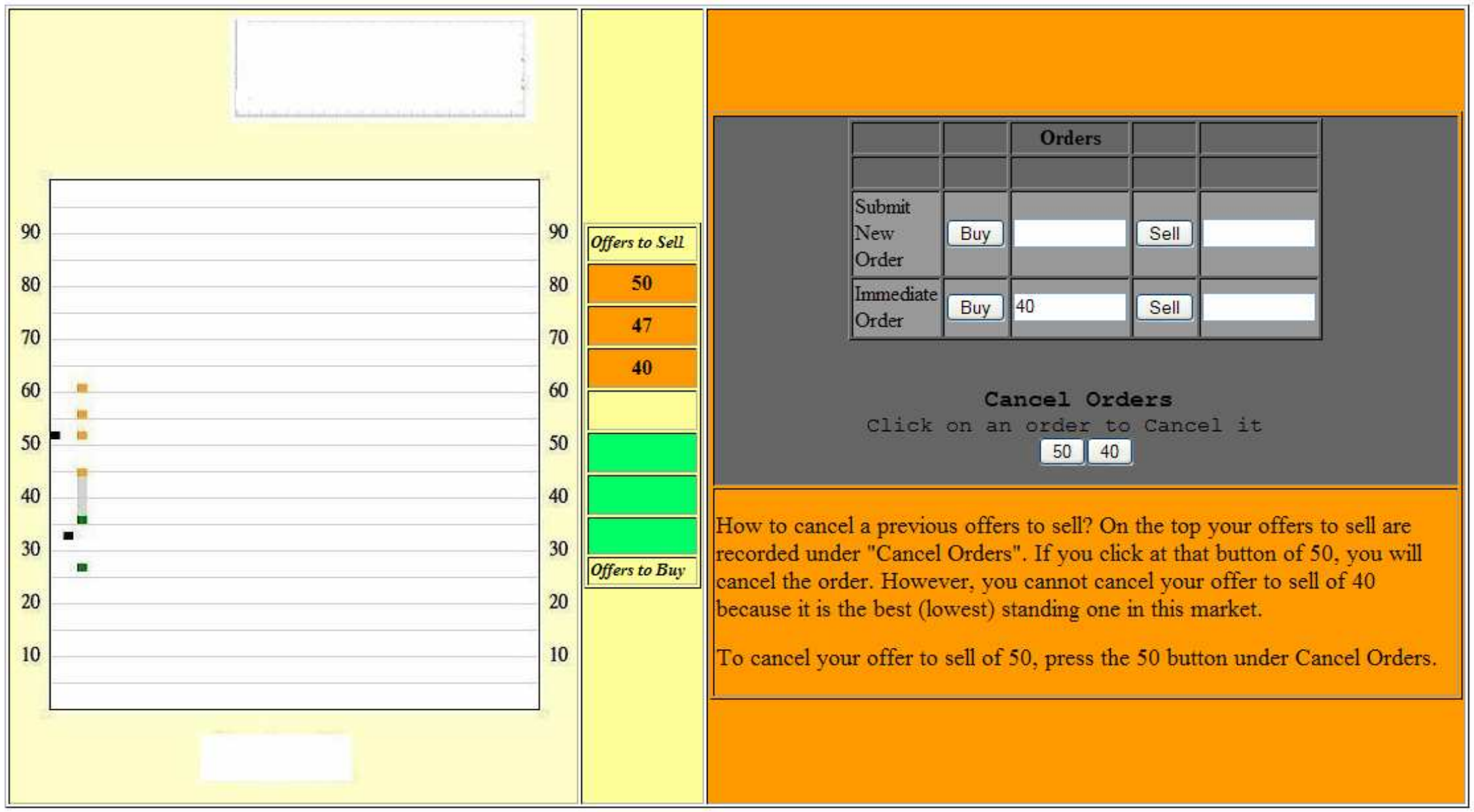




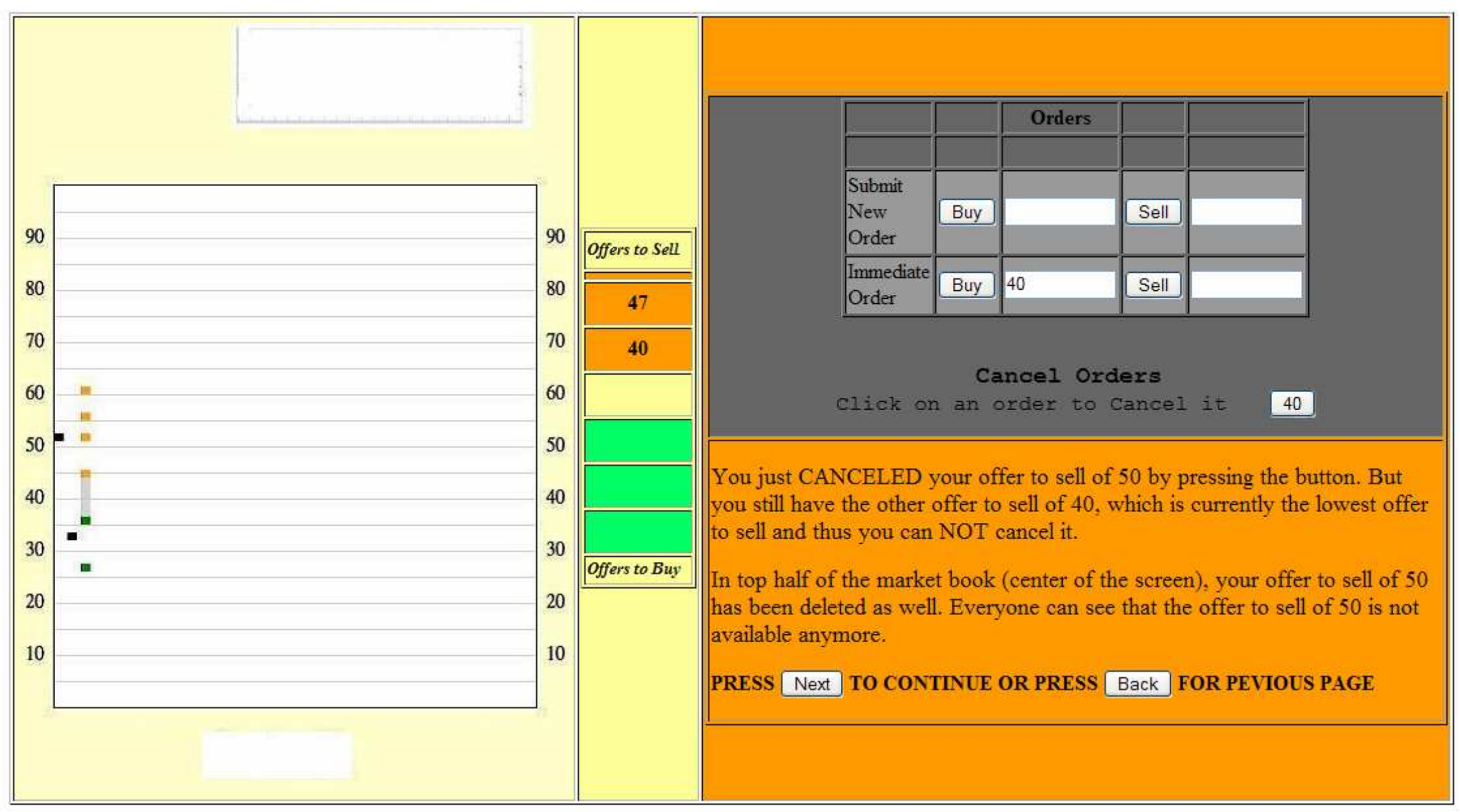




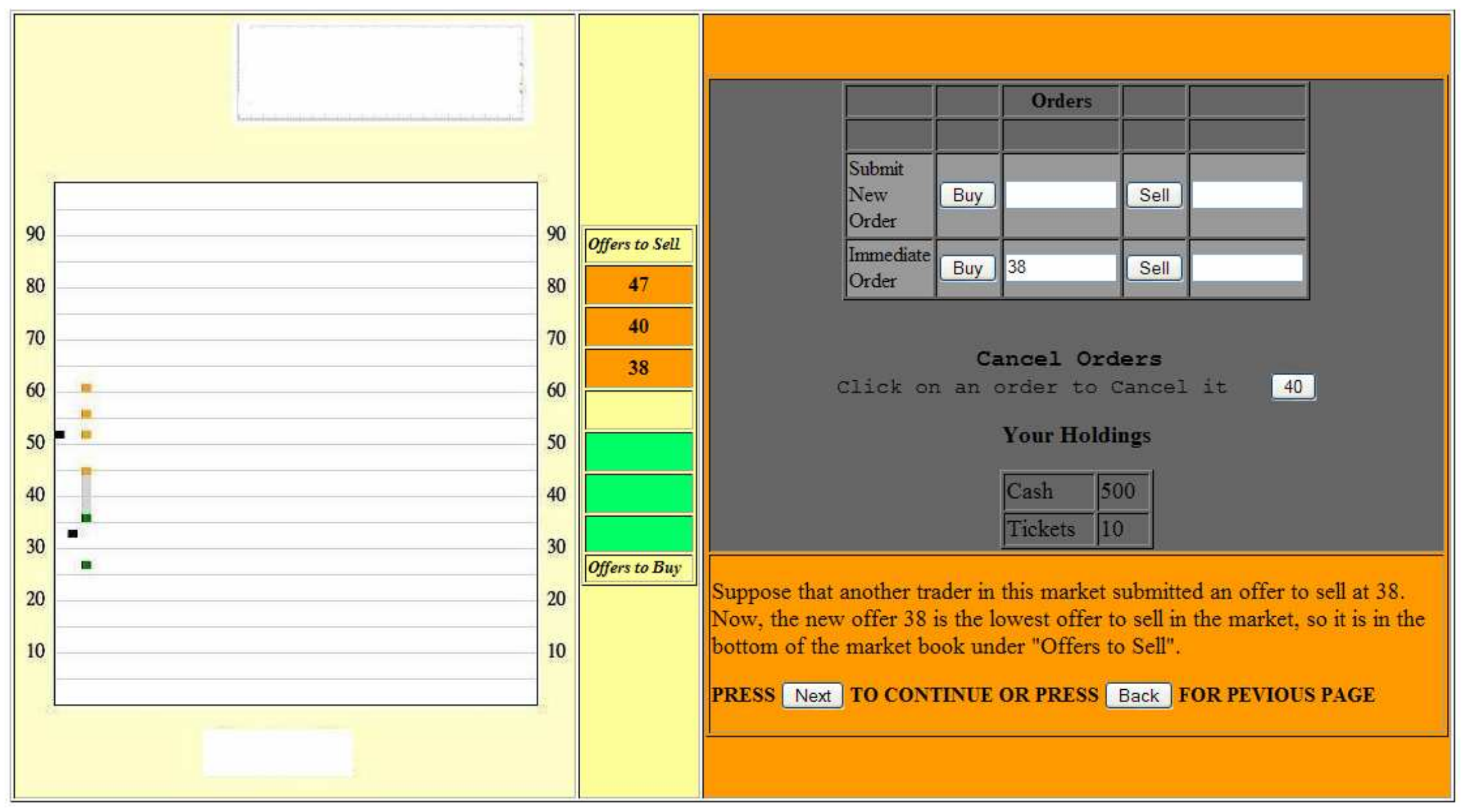




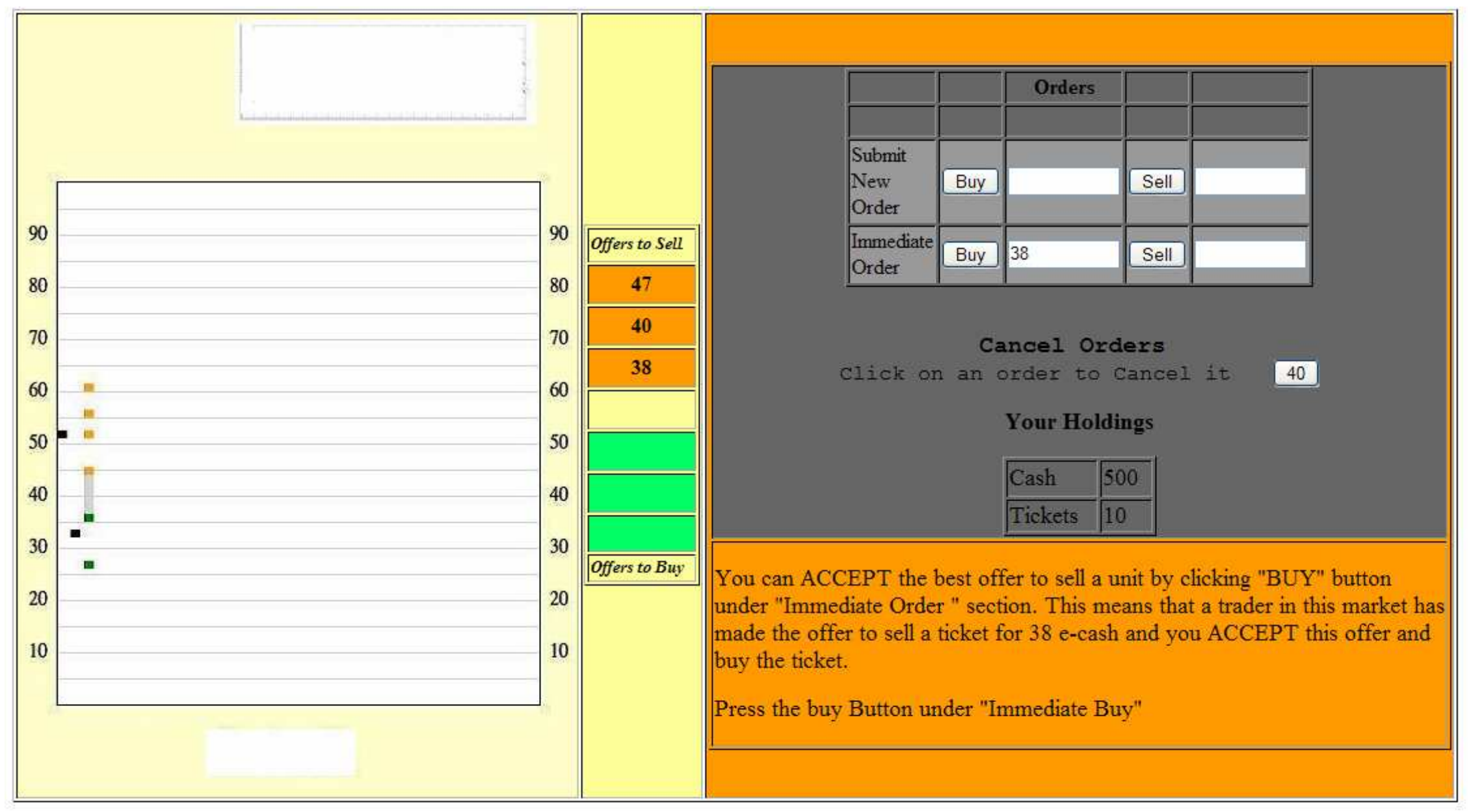




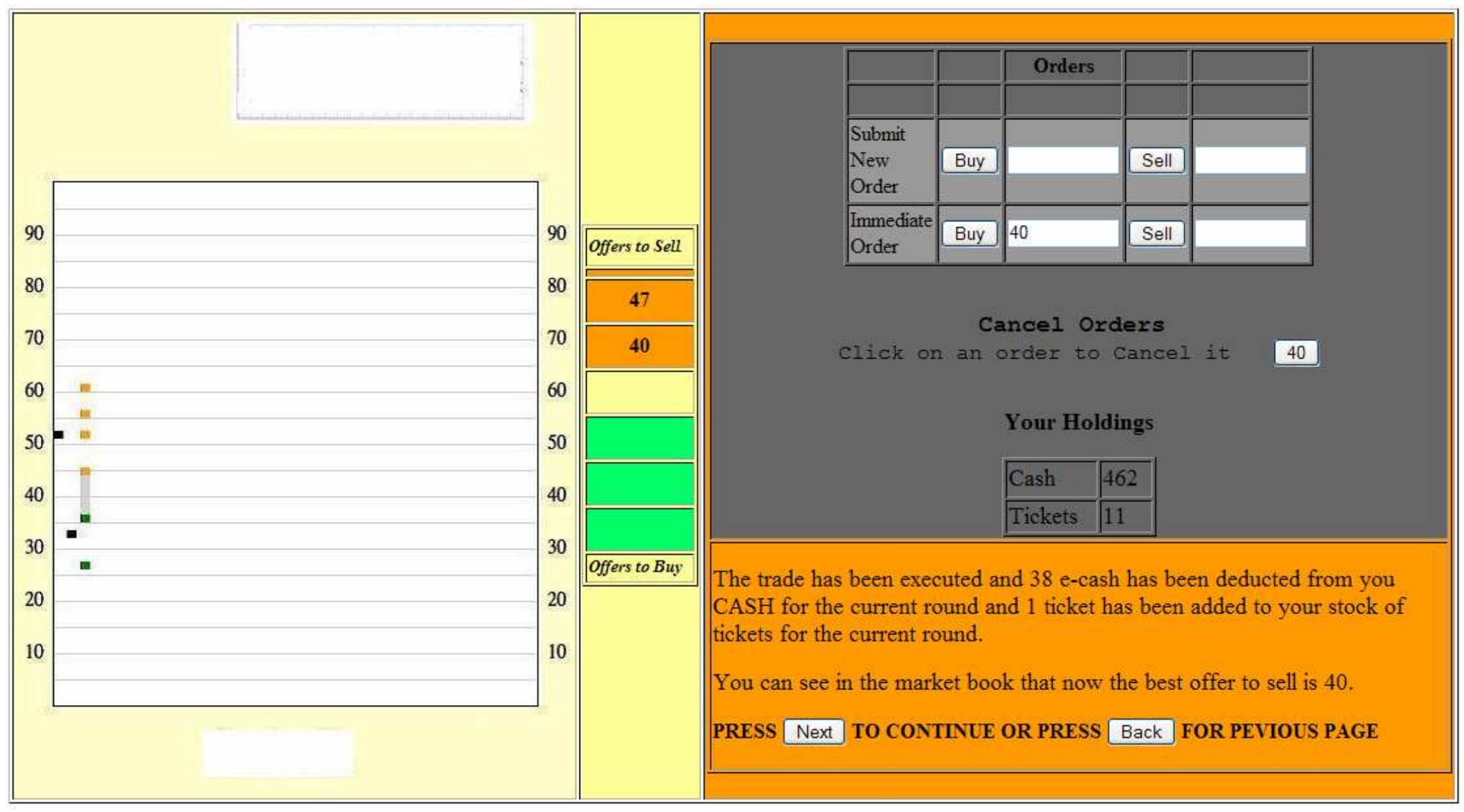




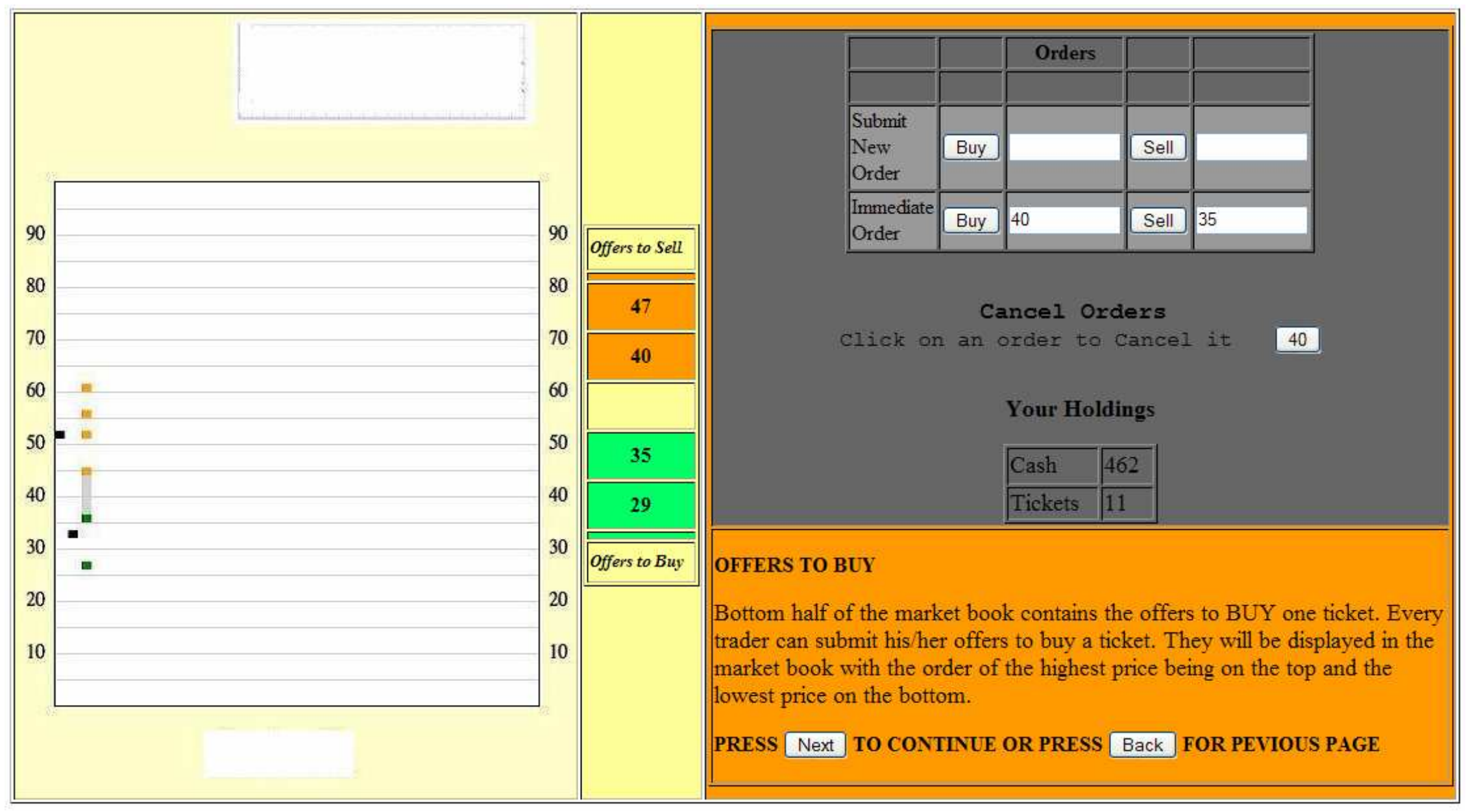




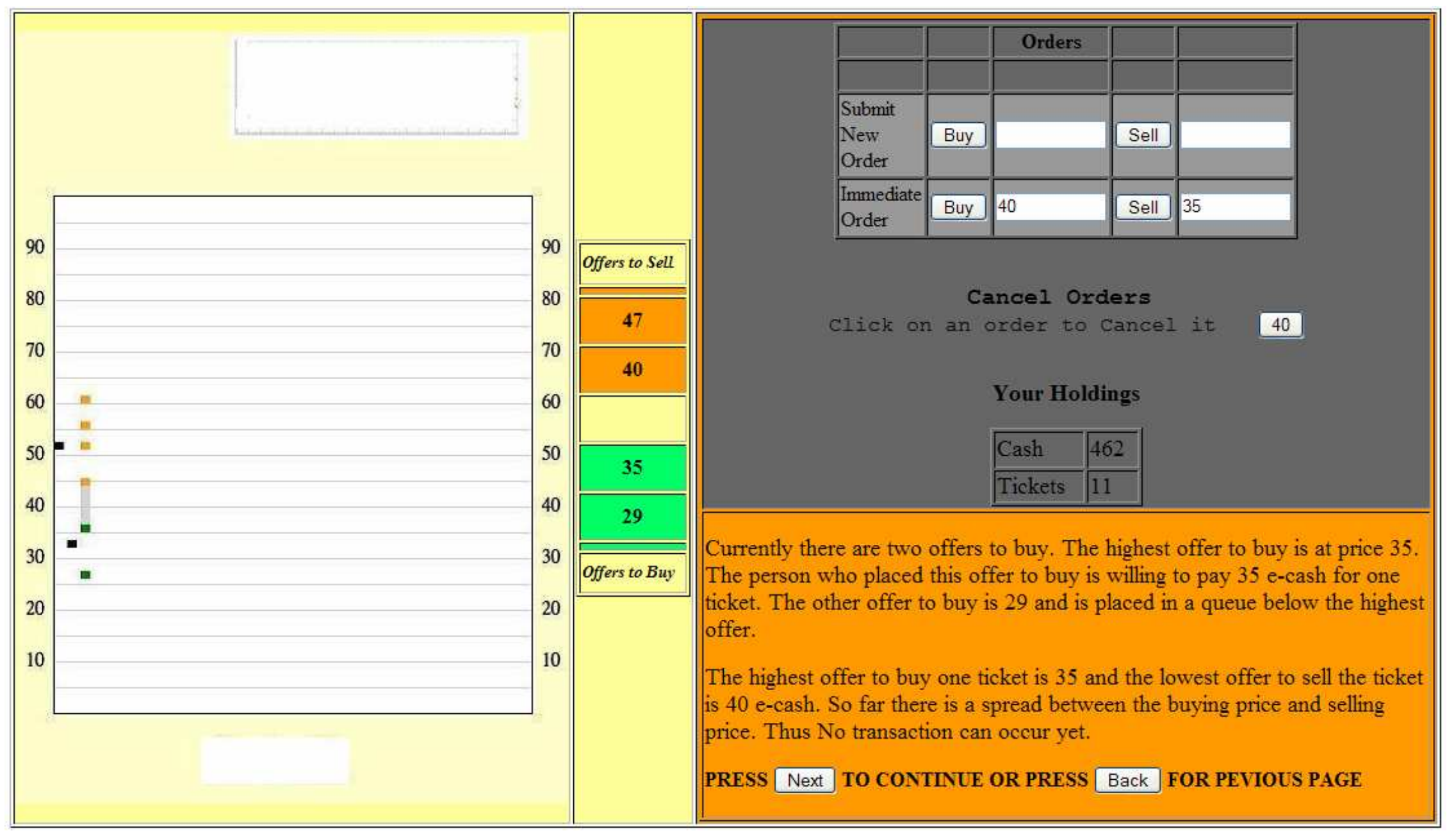




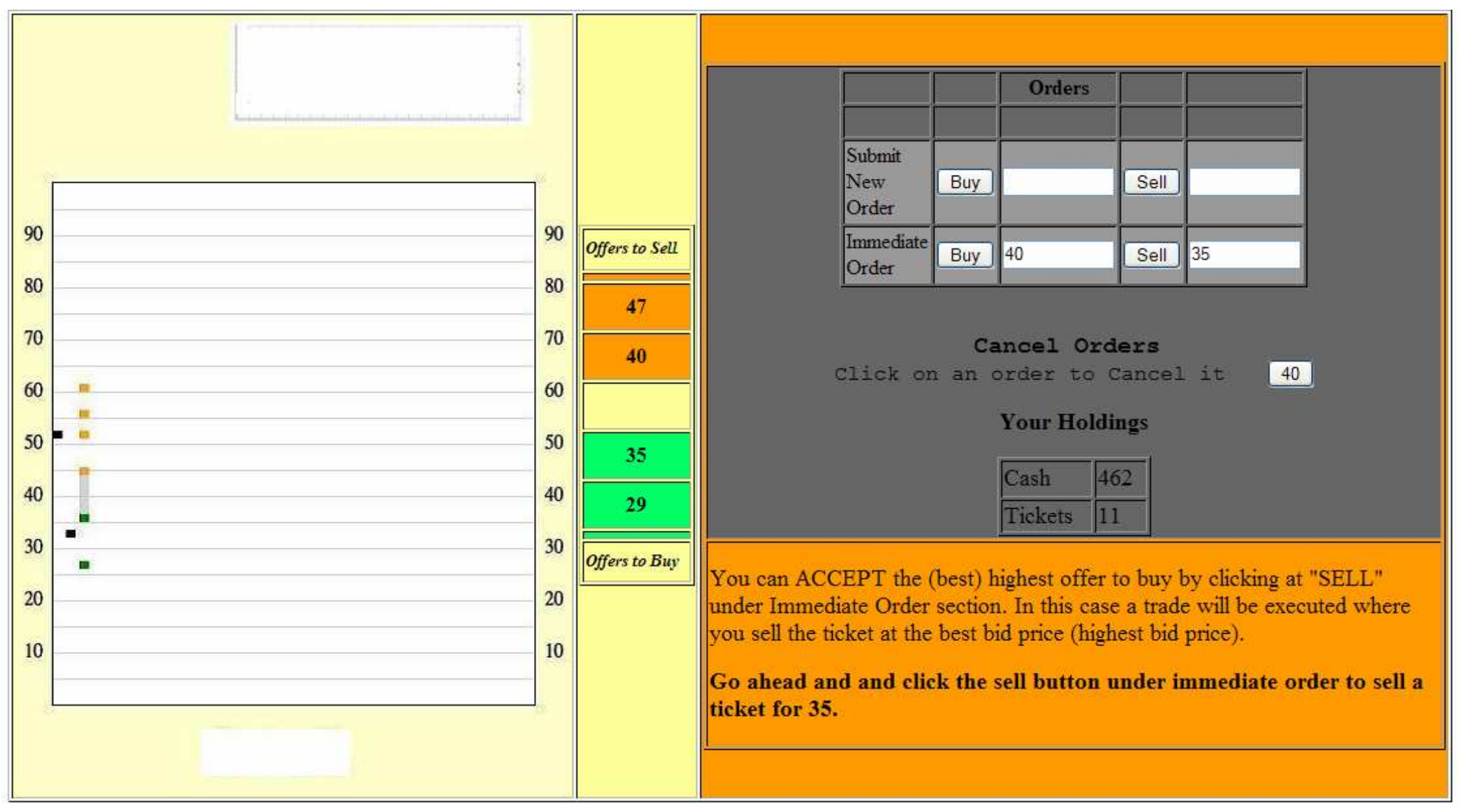




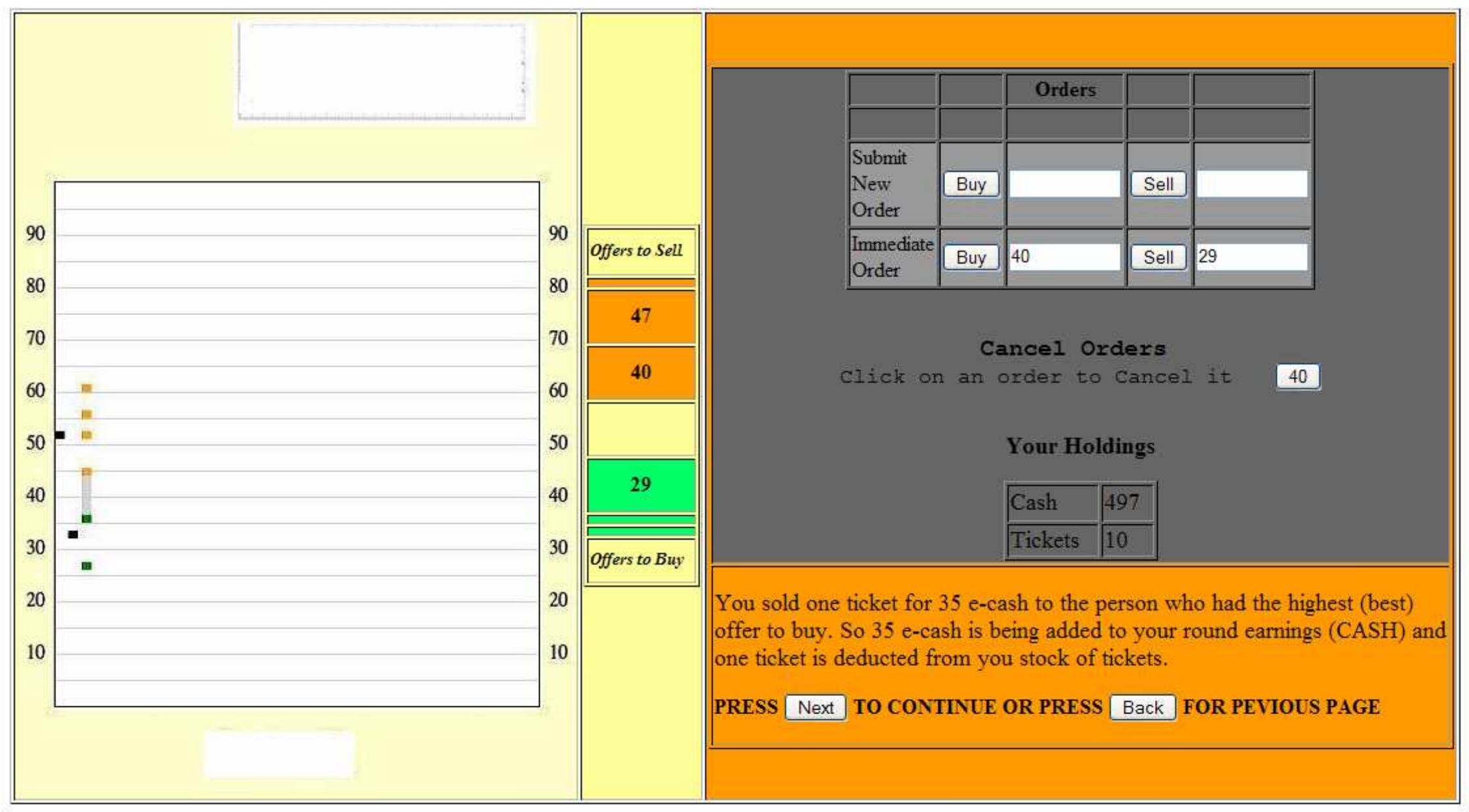




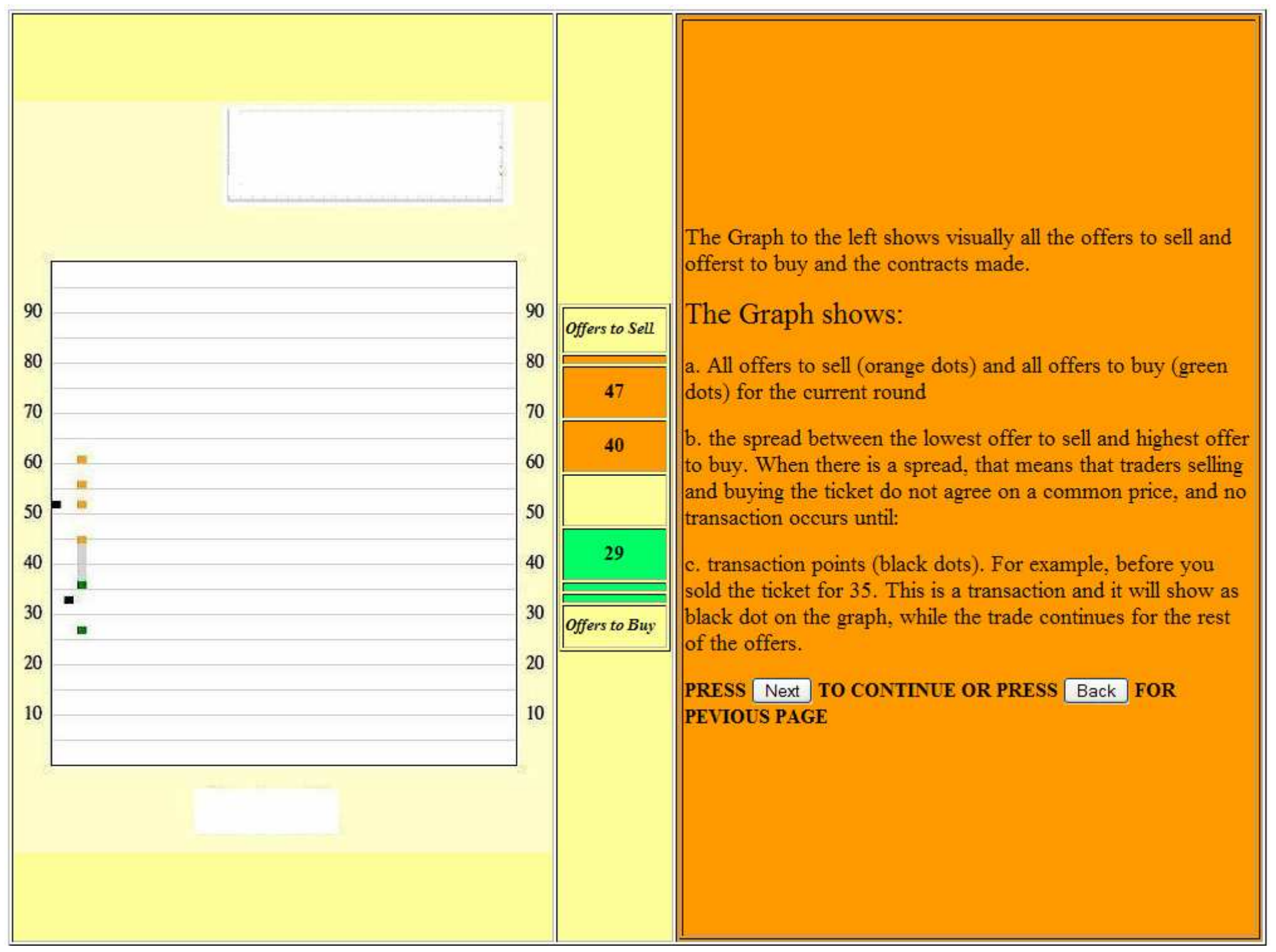

Page 49 of 50 


\section{Summary}

1. You will begin the experiment with some cash and some units of tickets.

2. Each ticket generates a dividend of either 10 or 100 at the end of the trading period. The likelihood of each outcome will be given to you.

3. You can submit Bids to Buy a ticket and Offers to Sell a ticket.

4. The experiment will last for 1 period. At the end of the period, there will be a dividend. Tickets expire after the final period and have no other value to you. 


\section{Economic Science Institute Working Papers}

2008

08-03 Thomas, C. and Wilson, B. Horizontal Product Differentiation in Auctions and Multilateral Negotiations.

08-02 Oprea, R., Wilson, B. and Zillante, A. War of Attrition: Evidence from a Laboratory Experiment on Market Exit.

08-01 Oprea, R., Porter, D., Hibbert, C., Hanson, R. and Tila, D. Can Manipulators Mislead Prediction Market Observers? 